\title{
CALAS CRÍTICAS EN LA TRANSMISIÓN MANUSCRITA DEL CANTAR DE MIO CID A PARTIR DE SUS COPIAS DIECIOCHESCAS
}

\author{
A critic revision about the manuscript transmission \\ of the Cantar de mio Cid in its copies from 18th century
}

\author{
Alberto ESCALANTE VARONA \\ Universidad de La Rioja \\ alberto.escalante@unirioja.es
}

Fecha de recepción: 12/03/2019

Fecha de aceptación definitiva: 08/06/2019

RESUMEN: En este artículo, realizaremos una revisión de la recepción y transmisión del Cantar de mio Cid en el siglo XVIII. Para ello, cotejaremos los testimonios del Cantar datados en este siglo (entre ellos, las copias de fray Sarmiento y Cándido María Trigueros) con una copia de comienzos del siglo XVI y el codex unicus medieval. Siguiendo el método crítico del error significativo, filiaremos los testimonios para detectar posibles nuevos subarquetipos en la transmisión manuscrita del Cantar desde la Edad Media hasta el siglo XVIII, y que pudieron ser determinantes para el conocimiento del texto en el Siglo de las Luces.

Palabras clave: crítica textual; estema; Disertación sobre el verso suelto y la rima; destierro del Cid; épica.

ABSTRACT: In this paper, we revise the reception process and the transmission of the Cantar de mio Cid in $18^{\text {th }}$ century. For this purpose, we compare the testimonies of the Cantar dated in this period (among these, the copies made by Sarmiento and Cándido María Trigueros) with a copy from the beginning of $16^{\text {th }}$ century and the Medieval codex unicus. We follow the critic method of the significant mistake to make the filiation of those testimonies. As a result, we propose the existence 
of archetypes in the manuscript transmission of the Cantar from Middle Ages to $18^{\text {th }}$ century, and that could be decisive for the knowledge of the text in Spanish Enlightenment.

Key words: textual criticism; stemma; Disertación sobre el verso suelto y la rima; banishment of Cid; epics.

\section{INTRODUCCIÓN}

Como es bien sabido en el campo de los estudios dieciochistas, el conocimiento crítico del Cantar de mio Cid, en cuanto a la lectura y comentario del códice medieval de Vivar, no se intensificó hasta la publicación de la edición de Tomás Antonio Sánchez, en 1779. No fue ni mucho menos un texto desconocido anteriormente, pero la unicidad del códice y su conservación en Vivar dificultaban su manejo directo. Solo contamos con unas pocas referencias sobre varios eruditos circunscritos al ámbito eclesiástico, como Sandoval, Berganza, Sarmiento o Trigueros. De ellos solo obtenemos noticias dispersas y copias de fragmentos, más o menos extensos, bien realizados sobre el códice medieval o sobre alguna copia intermedia; poco a poco, a partir de contribuciones críticas recientes (Aguilar Piñal, 1984; Montaner, 2007, 2011, 2018), se ha realizado un listado de todos estos testimonios, lo que nos sirve para trazar las vías de transmisión del texto cidiano a lo largo del tiempo.

Sin embargo, un cotejo exhaustivo de estas noticias arroja otros resultados que nos permiten plantearnos la posibilidad de que la difusión del Cantar de mio Cid, desde el códice de Vivar hasta la edición de Sánchez, fuese más extensa de lo que se ha pensado hasta ahora. Los testimonios sobre el Cantar localizados en el siglo XVIII resultan cruciales para poder establecer esta hipótesis.

Por ello, en el presente estudio partiremos de la identificación de todas las manifestaciones textuales, manuscritas e impresas, por las que se difundió el Cantar desde su copia medieval, en el códice de Vivar, hasta el siglo XIX. Sobre las fichas bibliográficas elaboradas, seleccionaremos los textos fechados en el siglo XVIII y rastrearemos el estado de la cuestión de aproximaciones críticas sobre ellos. A continuación, cotejaremos estas manifestaciones, para establecer un estema sobre el que poder extraer conclusiones acerca de las vías de transmisión del Cantar en el siglo XVIII.

\section{ESTADO DE LA CUESTIÓN: FUENTES PRIMARIAS Y ESTUDIOS CRÍTICOS}

2.1. Las copias del Cantar, desde el códice de Vivar hasta la edición de Sánchez

El códice medieval original donde se recoge el Cantar de mio Cid se conserva en la Biblioteca Nacional de España (signatura Vitr/7/17). Puede consultarse en una reproducción digital de alta calidad. Igualmente, cuenta con numerosas 
ediciones críticas, así como con ediciones paleográficas a cargo de Menéndez Pidal $(1911,1961)$ y Riaño Rodríguez y Gutiérrez Aja (2003).

Con posterioridad, se recogen varias noticias del Cantar, que listamos a continuación (tomamos como base las revisiones realizadas por Aguilar Piñal, 1984: 227-229, y Montaner, 2011: CCXCVI-CCCIII, y 2018: 56-57); a continuación, tras el listado, ofreceremos algunos datos sobre su clasificación y, en la medida de lo posible, precisaremos más su datación:

- Manuscrito de Juan Ruiz de Ulibarri (Biblioteca Nacional de España: MSS/6328). Año 1596. Copia manuscrita del códice de Vivar completo.

- Manuscrito de la Real Academia de la Historia (Ms. N-34; volumen facticio, ff. 96r.-100r.). Sin fecha exacta: Montaner lo data a finales del siglo XVI o comienzos del XVII. Copia de los versos 1-197.

- Fray Prudencio de Sandoval: Primera parte de las fundaciones de los monesterios del glorioso Padre San Benito [...]. Madrid: Imprenta de Luis Sánchez, 1601, f. 41v. Versos 1-4.

- Fray Francisco de Berganza: Antigüedades de España, propugnadas en las noticias de sus reyes y condes de Castilla la Vieja [...], parte primera. Madrid: Imprenta de Francisco del Hierro, 1719, p. 449. Versos 998-1013.

- Fray Martín Sarmiento:

- Obras manuscritas (Biblioteca Nacional de España: ms. 20377, ff. 148r.-195v.). Hacia 1745. Copia de fragmentos sueltos de todo el Cantar.

- Obras póstumas del Rmo. P. M. Fr. Martín Sarmiento benedictino, tomo primero. Madrid: Imprenta de Joaquín Ibarra, 1775, 244. Versos $1-10$.

- Cándido María Trigueros:

- Disertación sobre el verso suelto y la rima (Biblioteca Nacional de España: MSS/20056, ff. 63r.-69r.). Año 1766. Versos 1-197.

- El poeta filósofo o poesías filosóficas. Sevilla: Imprenta de Manuel Nicolás Vázquez y compañía, 1775, f. 7r. Versos 1-13.

- Copia de la Disertación (Biblioteca Colombina: manuscrito 58-4-26, ff. 53r.-58r.). Sin fecha exacta: finales del s. XVIII-comienzos del siglo XIX (antes de 1809). Versos 1-197.

- Copia de las historias de Fernán González y el Cid (Biblioteca Colombina: manuscrito 59-2-13, ff. 141r.-146r.). Sin fecha exacta: datado por la Biblioteca Colombina y por Montaner en el siglo XVIII. Versos 1-197.

- Tomás Antonio Sánchez: Colección de poesías castellanas anteriores al siglo XV, tomo I, Poema del Cid. Madrid: Imprenta de Antonio de Sancha, 1779. Cantar completo.

- El Cid. Poema antiguo (Biblioteca Universitaria de Oviedo: M-290). Cantar completo. Sin fecha exacta: datado por Montaner en el siglo XVIII. 
Por una parte, debemos separar las copias parciales de las completas. Entre las primeras, a su vez, debemos diferenciar entre un grupo formado por las copias de 197 versos, en los manuscritos de la RAH, Trigueros y dos testimonios de la Colombina. El manuscrito de Trigueros es muy interesante, pues en él nos indica que la noticia del Cantar le llegó por un manuscrito de su colección (Trigueros, 1766: f. 63r.):

En un tomo en quarto de varios manuscritos tengo, entre otros papeles, el que sigue, que juzgo ser escrito a los principios del siglo $1500^{1}$, y se supone copia del original, que se conserva en el concejo de Vivar. Yo no he tenido proporcion de averiguar el estado de su original, o de investigar si es contemporaneo al hecho de que habla; pero juzgo que son muy antiguos: [...].

Trigueros, así, da noticia de un manuscrito antiguo en el que se transmitió una parte del Cantar, y que hasta la fecha no ha sido localizado. Emplea estos versos del Cantar para justificar sus conclusiones eruditas sobre los orígenes de la poesía castellana y la naturaleza del verso suelto.

Por otra, los testimonios dieciochescos parten de los pocos versos copiados por Berganza y culminan en el manuscrito 59-2-13 de la Colombina, con ex libris autógrafo de Bartolomé José Gallardo en f. 58r., tal vez no podría fecharse con posterioridad a 1809, pues consideramos que el pacense rubricaría el manuscrito al manejarlo durante el periodo en que fue bibliotecario de las Cortes de Cádiz 2 . El manuscrito de Oviedo seguramente sea copia de la edición de Sánchez, tal y como sostiene Montaner (2018: 57), aunque no podemos fecharlo con seguridad: la única referencia temporal cierta reside en su ex libris, de 1851, en sus primeras hojas de guarda, donde se indica que el manuscrito fue propiedad del arqueólogo asturiano Sebastián de Soto Cortés. Por lo demás, su caligrafía es claramente dieciochesca: por tanto, podría datarse este manuscrito entre finales del siglo XVIII y, como muy tarde, comienzos del XIX.

1. Añadido sobre el renglón: "XV». Esta y otras anotaciones fueron efectuadas por Amador de los Ríos, quien, como académico de la Real Academia de Buenas Letras de Sevilla, tendría acceso a este manuscrito de Trigueros (texto que, por otra parte, plagió en numerosas ocasiones en su Historia de la literatura, como prueba Román Gutiérrez, 2017). Esto también explica cómo el manuscrito acabó en la Biblioteca Nacional, vendido por la familia de Amador, en contra de la voluntad de Trigueros, quien quiso que se conservase en la academia sevillana. Amador anota "XV" como parte de los apuntes que realiza sobre el manuscrito de Trigueros para la redacción de su Historia.

2. La firma aparece identificada como de Gallardo en la ficha bibliográfica del manuscrito, en el catálogo de la Biblioteca Colombina. También corresponde con la firma que LAMA HERnáNDEz (2015) localizó en un volumen facticio de la Colección de Cortes de los Reinos de León y Castilla, de 1836, en la que se conservan "marcas indiciarias de propiedad y de lectura» (2015: 184) realizadas por Gallardo: le agradecemos que realizase el cotejo de la rúbrica de este manuscrito de la Biblioteca Colombina con la contenida en dicho volumen de las Cortes, lo que terminó de confirmar la huella de Gallardo en esta copia de la Disertación. 


\subsection{Los testimonios dieciochescos sobre el Cid: estado de la cuestión crítica}

Sobre las copias dieciochescas, la crítica se ha centrado especialmente en la Disertación de Trigueros. El primero en localizar y estudiar este texto, dando noticia de la interesante copia de los versos del Cantar, fue Aguilar Piñal (1984, 1987, 2001). Por su parte, Román Gutiérrez (Trigueros, 2017) editó la Disertación completa junto con los versos.

Montaner ha centrado su investigación en el Cantar de mio Cid, lo que irremediablemente le lleva a rastrear su difusión con posterioridad a la Edad Media. En sendos trabajos $(2011,2018)$ revisaba el listado de testimonios: dio noticia de las copias de la Colombina y Oviedo (2018: 55-58) y propuso un estema (2018: 60) en el que filiaba los manuscritos dieciochescos (la copia de Trigueros en Colombina, 58-4-26, y el manuscrito facticio en Colombina con las historias del Cid y Fernán González, 59-2-13) como derivadas del testimonio de la RAH. A su vez, el manuscrito RAH diferiría de la copia de Ulibarri, siendo ambos copias del Cantar único. RAH, en conclusión, sería el manuscrito «del siglo 1500» que Trigueros dijo poseer.

Sobre estos datos, y sin menoscabo de la relevancia y calidad de las investigaciones ya realizadas, donde sus respectivos autores son autoridades incuestionables en la materia, consideramos que pueden realizarse otras interpretaciones. El cotejo de los testimonios dieciochescos con las copias modernas y el Cantar sugiere una revisión del estema, al que debemos añadir la copia autógrafa de la Disertación (BNE, Mss/20056), necesariamente anterior a la copia en la Colombina. También pueden incluirse los testimonios breves de Berganza y Sarmiento, así como El poeta filósofo, o Poesías filosóficas, de Trigueros: aunque son testimonios muy breves, y por tanto su inclusión en el estema es complicada, creemos que el cotejo nos permite intuir su posición en él.

\section{OBjetivos del ESTUdiO: RECENSIO (TESTIMONIOS Y METODOlOGÍA)}

Los testimonios sobre los que trabajaremos principalmente son los siguientes:

- $\quad V$ designa al códice del Cantar que se conservó en Vivar y que hoy se localiza en la Biblioteca Nacional; para la colación hemos empleado las transcripciones paleográficas realizadas por Menéndez Pidal (1911, 1961) y Riaño Rodríguez y Gutiérrez Aja (2003), así como hemos consultado la reproducción facsimilar del códice cuando lo hemos considerado necesario. También remitimos a la edición crítica de Montaner (2011).

- $\quad R$ es la copia parcial conservada hoy en día en la Biblioteca de la Real Academia de la Historia (Ms. N-34).

- $\quad$ T es el autógrafo de la Disertación de Trigueros (BNE, Mss/20056). Consultamos también el manuscrito T', copia de la Disertación con ex libris de Bartolomé José Gallardo y conservada en la Biblioteca Colombina 
(58-4-26), a la hora de confirmar las variantes separativas entre $T$ y el resto de testimonios. También cotejamos el testimonio T2, otra copia de los diez primeros versos del Cantar que Trigueros ofrece en sus Poesías filosóficas.

- $\quad$, por último, es el manuscrito facticio conservado en la Biblioteca Colombina (59-2-13), con los mencionados 197 versos más la historia de Fernán González.

Tendremos también en cuenta los testimonios de Ulibarri, Sarmiento, Berganza y Sánchez. Sin embargo, estos no constituirán una parte destacable de la collatio, que se desarrollará principalmente entre los manuscritos en los que se transmite la misma copia de los primeros 197 versos del Cantar ${ }^{3}$. Por ello, estos testimonios restantes no serán referidos por medio de inicial o sigla.

\section{COLLATIO}

Para la collatio de los testimonios, emplearemos como base metodológica el manual de Blecua (2001): aunque sea una aportación ya clásica (se editó por primera vez en 1983), sigue siendo de consulta indispensable, tanto por su autoridad (supuso la consagración en los estudios hispánicos del método de crítica textual por el error significativo) como por la rigurosidad de su planteamiento. Nos interesa, sobre todo, trabajar sobre su tipología de los errores y su clasificación de las lecciones y errores en el examen de las variantes durante la fase de la collatio. Siguiendo este método, discriminaremos entre lecciones equipolentes, enfrentadas, que aparentemente sean igual de correctas, y lecciones adiáforas, errores comunes (2001: 49-57) sobre los que podremos plantear ramas separativas en el estema. Justificaremos en qué caso nos encontramos con errores poligenéticos y accidentales, explicables como resultado del proceso natural de copia y de correcciones conscientes que realiza el copista. También tendremos que prestar especial atención a las variantes de copista, producidas generalmente por trivializaciones (por proceso, ante todo, de lectio facilior) sobre la lectura original, pero también por modificaciones voluntarias: en ambos casos, tendremos que determinar en qué casos son errores separativos.

3. Trabajamos con reproducciones digitales de estos testimonios. Por ello, queremos agradecerle al personal de la Biblioteca Nacional, la Biblioteca Colombina y la Biblioteca de la Real Academia de Historia por habernos proporcionado estos materiales. Sobre todo, queremos destacar que el manuscrito de la RAH permanecía perdido, y así se indica en su catálogo de 2005, pero gracias al descubrimiento del mismo expuesto por el profesor Montaner hemos podido solicitar su reproducción, según la signatura que MonTANER cita (2018: 56) y que le fue indicada por Francisco Bautista, a quien le agradece la información que le proporciona sobre los manuscritos que desconocía cuando realizó el rastreo de codex descripti del Cantar en su edición de 2011. 
Aun así, cabe señalar que dos de los manuscritos presentan errores ajenos a la copia, por motivos de conservación o manipulación indebida. En el manuscrito de la RAH no puede leerse el final de algunos versos situados al margen derecho del verso de los folios, puesto que el cosido de los cuadernos impide acceder al texto. Y en el manuscrito autógrafo de Trigueros falta la mitad del último folio, lo que impide que podamos leer los versos 180-193 y prácticamente el segundo hemistiquio del verso 194.

La collatio que nos interesa realizar, como ya hemos dicho, es sobre los testimonios en los que se copian los primeros 197 versos del Cantar. Parece evidente que todos ellos provienen de un mismo manuscrito común, que Montaner identificó como $R$. El cotejo con la copia de Ulibarri ofrece tantos errores separativos que excederían por mucho los límites de nuestro trabajo y que prueban que esta no tuvo ninguna relación con estas copias de los 197 versos. Por tanto, la desechamos de nuestro cotejo, salvo en un caso puntual: su relación con las noticias que Berganza y Sarmiento dan del Cantar.

\subsection{El testimonio de Sarmiento y su posible posición en el estema}

En las Antigüedades de España, Berganza (1719: 449) copia los versos 9981013 del Cantar, indicando que ha visto el códice de Vivar. Puesto que son versos ajenos al "traslado" de los 197 primeros versos contenidos en $R$, y puesto que el cotejo con la copia de Ulibarri no arroja similitudes, consideramos que, efectivamente, Berganza realizó su copia sobre el códice medieval.

Diferentes conclusiones sacamos del cotejo de los testimonios dados por Sarmiento sobre el texto cidiano. Es evidente que, en su copia de fragmentos del Cantar, fechada en torno a 1745, Sarmiento (1745: f. 148r.) copia a Ulibarri, puesto que declara que "un curioso" se la ha prestado; solo de esta forma pudo Sarmiento copiar y comentar fragmentos completos del Cantar, sin haber consultado el códice de Vivar.

Pero al remitir por segunda vez al Cantar, en la noticia incluida en sus Obras póstumas, Sarmiento (1775: 244) no remite a Ulibarri. Sobre esta copia de los diez primeros versos indica:

A esta clase [de versos] pertenece un fragmento poético de la Historia del Cid, que he visto manuescrito. Sacóse de un Códice en pergamino, que se guarda en el Archivo del Concejo de Vivar, patria del mismo Cid Campeador; pero sumamente alterado dicho fragmento, así en la medida, como en los consonantes. [...] He copiado puntualmente la copia moderna; y me parece quimérico que esté tan alterado, é inconexo el contexto en el antiquísimo manuescrito de Vivar; pero como no he visto dicho Códice, ha sido forzoso contentarme con lo propuesto.

Aunque parecería evidente que Sarmiento volviese a consultar la copia de Ulibarri en esta segunda ocasión, pues ya había trabajado con ella, el cotejo de estos 
diez versos no arroja similitudes con Ulibarri, y sí con $R$. Transcribimos estos versos a continuación (1775: 245):

De los sos ojos tan fuertemente lorando,

Tornaba la cabeza, é estábalos catando, Vió puertas abiertas, é uzos sin canadas, Alcandaras vacías, sin pieles, é sin mantos,

E sin Falcones, et sin Adzores mudados, Sospiró mio Zid, cá mucho avíe grandes coidados.

Fabló mio Zid bien, é tan mejorado:

Grado á tí, Señor Padre, que estás en alto:

Esto me han envuelto mis enemigos malos:

Allí piensan de aguijar, alí soltan las riendas.

En el v. 7, la lectura "mejorado» no procede de Ulibarri (donde se lee «mesurado»); tampoco en el v. 8, "Señor Padre» (frente a "Senor»); ni "envuelto", en el v. 9 (frente a "an buelto»); ni "alí soltan», en el v. 10 (frente a "alli sueltan»).

Sin embargo, todas estas lecturas de Sarmiento son casi siempre conjuntivas con las de $R$. Debemos también cotejarlas con $V$. La lectura «mejorado» es un error separativo de Sarmiento, con respecto a $R$, «mesorado», y $V$ y Ulibarri, donde se lee "mesurado": pero la grafía para "S» de $R$ puede ser confundida con «", por lo que se trata de un error de sustitución que permite filiar a Sarmiento como derivado de $R$. La lectura "señor Padre», en el v. 8, es conjuntiva con $V$, "Sennor padre», y $R$, «señor Padre», pero separativa con Ulibarri, "Senor», quien comete un error de supresión de palabra. La lectura "han envuelto" es conjuntiva con "an em buelto" de $R$, aplicando Sarmiento una actualización, pero es separativa con respecto a $V$ y Ulibarri ("an buelto»). Por último, la lectura "alí soltan» coincide con la que ofrece $R$, pero esta es separativa con respecto a $V$ y Ulibarri ("alli sueltan»).

Por tanto, los diez versos copiados, pese a ser una muestra cuantitativamente insuficiente, nos despiertan una duda razonable de que Sarmiento, en esta ocasión, consultó $R$, que también era una "copia moderna». Tendría sentido, además, puesto que la copia de Ulibarri le llegó en préstamo temporal, según declaró Sarmiento; en esta segunda ocasión, tiene que recurrir a otro manuscrito para poder dar noticia del Cantar. Aun así, y debido a la brevedad de la muestra, solo podemos plantear esta conclusión como hipótesis provisional de trabajo, pendiente de confirmación (volveremos sobre ella más adelante, cuando propongamos nuestro estema).

4.2. El testimonio de Trigueros y el manuscrito de la Colombina en el estema de copias cidianas

El cotejo de los manuscritos con los 197 versos debe realizarse en varias direcciones. En primer lugar, tendremos que señalar los errores comunes a los tres testimonios $R, T$ y $C$ con respecto a $V$ : 
CALAS CRÍTICAS EN LA TRANSMISIÓN MANUSCRITA DEL CANTAR DE MIO CID A PARTIR DE SUS COPIAS DIECIOCHESCAS

\begin{tabular}{|c|l|l|l|l|}
\hline V. & \multicolumn{1}{|c|}{$V$} & \multicolumn{1}{c|}{$R$} & \multicolumn{1}{c|}{$C$} \\
\hline 1 & $\begin{array}{l}\text { tan fuerte mientre } \\
\text { lorando }\end{array}$ & $\begin{array}{l}\text { tan fuertemente } \\
\text { lorando }\end{array}$ & $\begin{array}{l}\text { tan fuertemente } \\
\text { lorando }\end{array}$ & $\begin{array}{l}\text { tan fuertemente } \\
\text { lorando }\end{array}$ \\
\hline 74 & $\begin{array}{l}\text { En ira del Rey } \\
\text { alffonsso yo sere } \\
\text { metido }\end{array}$ & $\begin{array}{l}\text { E en yra del Rey } \\
\text { Alfonso men sere } \\
\text { metido }\end{array}$ & $\begin{array}{l}\text { en ira del Rei } \\
\text { Alfonso non sere } \\
\text { metido }\end{array}$ & $\begin{array}{l}\text { en yra del Rey } \\
\text { Alfonso non sere } \\
\text { metido }\end{array}$ \\
\hline 86 & $\begin{array}{l}\text { Yncamos las } \\
\text { darena, ca bien } \\
\text { seran } \text { pesadas }\end{array}$ & $\begin{array}{l}\text { Fenchiremos las } \\
\text { de arena ca bien } \\
\text { seran pesadas }\end{array}$ & $\begin{array}{l}\text { hinchiremos las } \\
\text { darena ca bien } \\
\text { seran pesadas }\end{array}$ & $\begin{array}{l}\text { hinchiremos las } \\
\text { darena ca bien } \\
\text { seran pesadas }\end{array}$ \\
\hline
\end{tabular}

En el primer caso, la lectio facilior de «fuertemente» no constituye por sí misma un error conjuntivo, puesto que las tres lecturas de los manuscritos $R, T$ y $C$ pueden explicarse como actualizaciones poligenéticas del «fuertemientre» original. Igualmente, $T$ y $C$ podrían haber seguido la actualización ya presente en $R$.

Sin embargo, los dos restantes plantean más dudas, que nos animan a cuestionar el estema original. Los testimonios $R, T$ y $C$ proponen una lectura conjuntiva "men/non" que se separa de $V$, «yo". Lo mismo ocurre con "fenchiremos/hinchiremos» con respecto a "yncamos»". En ambos casos, puede entenderse que $T$ y $C$ trivializan la lectura de $R$, de la que supuestamente partirían. Así, «non» supondría tal vez un error poligenético ante la incapacidad de ambos copistas de entender las grafías de "men", o de comprender el significado de la palabra. Igual ocurriría con "hinchiremos", que sería actualización de "fenchiremos" y su grafía «f-» que enmudece y deriva en «h-». Como resultado, los errores de $R$ con respecto a $V$ serían claramente separativos con respecto a otras copias derivadas directamente del Cantar. Podría entenderse que las soluciones de $T$ y $C$ son soluciones poligenéticas, pero, de ser así, resultarían coincidencias poco probables.

\begin{tabular}{|c|l|l|l|l|}
\hline V. & \multicolumn{1}{|c|}{$V$} & \multicolumn{1}{c|}{$R$} & \multicolumn{1}{c|}{$T$} & \multicolumn{1}{c|}{$C$} \\
\hline 142 & $\begin{array}{l}\text { Amos [todos] tred } \\
\text { alcampeador con } \\
\text { tado }\end{array}$ & $\begin{array}{l}\text { Amos todos traed } \\
\text { al campeador } \\
\text { contado }\end{array}$ & $\begin{array}{l}\text { Amos vos traed } \\
\text { al Campeador } \\
\text { contado }\end{array}$ & $\begin{array}{l}\text { Amos todos tred } \\
\text { al campeador } \\
\text { contado }\end{array}$ \\
\hline
\end{tabular}

En el caso de "amos tred», localizamos una peculiaridad que refuerza la posibilidad de separación en el estema entre estos tres testimonios modernos. en el códice de Vivar se intercaló posteriormente el pronombre "todos», tal vez para completar la medida del verso, por alguien que interpretó erróneamente «tred»

4. Ulibarri lee "hinchemos", y Pellicer, en nota marginal, lee "yncimos». Es evidente que el término producía problemas a los copistas antiguos. 
como «tres". Todos los testimonios posteriores parten de esta modificación presente en el códice, si bien adoptando diferentes soluciones.

No tendría sentido realizar una síncopa en "tred», en $C$, una vez $R$, el supuesto testimonio del que parte, ha actualizado el verbo y se ha producido una epéntesis. Además, el cotejo prueba que esta lectura de $C$ coincide con la de $V$, mientras que $R$ y $T$ innovan de manera independiente (en $T$, "amos vos traed" es el resultado de una mala lectura de «VOS» en lugar de «todos»; $R$ y $C$ conservan el pronombre).

Ante estas y otras dudas, debemos realizar el cotejo sistemático de $R$ con los otros testimonios para replantearnos sus interdependencias. Así, $R$ presenta numerosas lecturas que no resultan conjuntivas con respecto a $T$ y $C$. Al contrario, en $R$ localizamos notables errores separativos con respecto a estos dos manuscritos. Ofrecemos a continuación dichas variantes significativas.

- Lecturas separativas entre $R$ y $T / C$.

\begin{tabular}{|c|c|c|c|c|}
\hline V. & V & $R$ & $T$ & C \\
\hline Íncipit $^{6}$ & & $\begin{array}{l}\text { Versos de la } \\
\text { Historia del } \\
\text { Çid Rui diaz } \\
\text { Campeador / } \\
\text { sacados de un } \\
\text { libro antiguo } \\
\text { escripto en } \\
\text { pergamino que } \\
\text { el consejo de } \\
\text { viuar tiene en sus } \\
\text { Archiuos/faltan } \\
\text { muchas hojas y } \\
\text { lo q se halla es } \\
\text { desde el destierro } \\
\text { / } \\
\text { Hizieron hazer } \\
\text { esta Historia en el } \\
\text { verso q entonces } \\
\text { se usaba los } \\
\text { Reyes nietos del } \\
\text { çid } ~\end{array}$ & $\begin{array}{l}\text { Este es un } \\
\text { traslado del } \\
\text { Historia del } \\
\text { Çid Rui Diaz } \\
\text { Campeador } \\
\text { sacado de un } \\
\text { libro antiguo } \\
\text { escripto en } \\
\text { pergamino que } \\
\text { el Concejo de } \\
\text { Bibar tiene en } \\
\text { sus archivos, el } \\
\text { tenor del es el } \\
\text { que sigue. }\end{array}$ & $\begin{array}{l}\text { Este es un traslado } \\
\text { de la Historia } \\
\text { del Çid Rui Diaz } \\
\text { Campeador. } \\
\text { sacado de un libro } \\
\text { antiguo escripto } \\
\text { en pergamino. } \\
\text { que el Conçejo } \\
\text { de Bibar tiene en } \\
\text { sus archivos el } \\
\text { tenor del. es el } \\
\text { siguiente. }\end{array}$ \\
\hline
\end{tabular}

5. MenÉndez PIdal (1911: 913) fecha esta modificación en el siglo XV; MonTANer (2011: 566), en el XIV. Esto implica que, en primera instancia, todas las copias que estamos cotejando proceden del códice de Vivar, donde aparece esta lectura.

6. Debemos aclarar que el íncipit no constituye un error en el sentido estrictamente ecdótico, pero lo incluimos en la tabla porque supone una variante significativa y crucial a la hora de filiar los 
CALAS CRÍTICAS EN LA TRANSMISIÓN MANUSCRITA DEL CANTAR DE MIO CID A PARTIR DE SUS COPIAS DIECIOCHESCAS

\begin{tabular}{|c|c|c|c|c|}
\hline V. & V & $R$ & $T$ & $C$ \\
\hline 29 & $\begin{array}{l}\text { Grande duelo auien } \\
\text { las yentes xpistianas }\end{array}$ & $\begin{array}{l}\text { grande duelo auien } \\
\text { las compañas } \\
\text { christianas }\end{array}$ & $\begin{array}{l}\text { Grande duelo } \\
\text { avien las gentes } \\
\text { christianas }\end{array}$ & $\begin{array}{l}\text { grande duelo auien } \\
\text { las yentes christianas }\end{array}$ \\
\hline 33 & $\begin{array}{l}\text { Por miedo del Rey } \\
\text { alfonsso }\end{array}$ & $\begin{array}{l}\text { por pauor del Rey } \\
\text { alfonso }\end{array}$ & $\begin{array}{l}\text { por miedo del Rei } \\
\text { Alfonso }\end{array}$ & $\begin{array}{l}\text { por miedo del Rey } \\
\text { Alfonso }\end{array}$ \\
\hline 33 & $\begin{array}{l}\text { que assi lo auien } \\
\text { parado }\end{array}$ & $\begin{array}{l}\text { ca asi lo auie } \\
\text { par[ilegible }]^{8}\end{array}$ & $\begin{array}{l}\text { que asi lo avie } \\
\text { parado }\end{array}$ & $\begin{array}{l}\text { que asi lo auie } \\
\text { parado }\end{array}$ \\
\hline 38 & $\begin{array}{l}\text { Saco el pie del } \\
\text { estribera }\end{array}$ & $\begin{array}{l}\text { Exio el pie del } \\
\text { estribera }\end{array}$ & $\begin{array}{l}\text { Saco el pie del } \\
\text { estrivera }\end{array}$ & $\begin{array}{l}\text { Saco el pie del } \\
\text { estribera }\end{array}$ \\
\hline 38 & Una feridal daua & Mal ferida daba & Una feridal daba & Una feridal daua \\
\hline 44 & $\begin{array}{l}\text { Non uos osariemos } \\
\text { abrir ni } n \text { coger por } \\
\text { nada }\end{array}$ & $\begin{array}{l}\text { non vos osariemos } \\
\text { colar nin coger por } \\
\text { nada }\end{array}$ & $\begin{array}{l}\text { non vos osariemos } \\
\text { abrir nin coger por } \\
\text { nada }\end{array}$ & $\begin{array}{l}\text { non vos osariemos } \\
\text { abrir nin coger por } \\
\text { nada }\end{array}$ \\
\hline 47 & enel nuestro mal & enel nueso mal & en el nuestro mal & en el nuestro mal \\
\hline 47 & $\begin{array}{l}\text { uos non ganades } \\
\text { nada }\end{array}$ & $\begin{array}{l}\text { vos non tolledes } \\
\text { nada }\end{array}$ & $\begin{array}{l}\text { vos non ganades } \\
\text { nada }\end{array}$ & $\begin{array}{l}\text { vos non ganades } \\
\text { nada }\end{array}$ \\
\hline 49 & tornos pora su casa & $\begin{array}{l}\text { erguiose para su } \\
\text { casa }\end{array}$ & tornós para su casa & tornos para su casa \\
\hline 50 & Ya lo vee el çid & Ya lo otea el cid & Ya lo vee el cid & Ya lo vee el Çid \\
\hline 55 & Salio por la puerta & Exio por la puerta & Salio por la puerta & Salio por la puerta \\
\hline 56 & en la glera posaua & en la glera parava & en la Glera posaba & en la glera posaua \\
\hline 64 & $\begin{array}{l}\text { Non le osarien } \\
\text { uender almenos } \\
\text { dinarada }\end{array}$ & $\begin{array}{l}\text { Non le osaran } \\
\text { vender nin menos } \\
\text { dinerada }\end{array}$ & $\begin{array}{l}\text { non losarien } \\
\text { vender al menos } \\
\text { dinarada }\end{array}$ & $\begin{array}{l}\text { non le osarien } \\
\text { vender al menos } \\
\text { dinarada }\end{array}$ \\
\hline $80-81$ & $\begin{array}{l}\text { doblar uos he la } \\
\text { soldada. / Espeso e } \\
\text { el oro }\end{array}$ & $\begin{array}{l}\text { doblaros he la } \\
\text { soldada / el peso e } \\
\text { el oro }\end{array}$ & $\begin{array}{l}\text { doblarvos e la } \\
\text { soldada / espeso e } \\
\text { el oro }\end{array}$ & $\begin{array}{l}\text { doblar vos e la } \\
\text { soldada. / espeso, e } \\
\text { el oro }\end{array}$ \\
\hline 83 & $\begin{array}{l}\text { e huebos me } \\
\text { serie pora toda mi } \\
\text { compana }\end{array}$ & $\begin{array}{l}\text { e mas mancarie } \\
\text { para toda mi } \\
\text { compaña }\end{array}$ & $\begin{array}{l}\text { e huebos me } \\
\text { serie para toda mi } \\
\text { compaña }\end{array}$ & $\begin{array}{l}\text { e huebos me } \\
\text { serie para toda mi } \\
\text { compaña }\end{array}$ \\
\hline
\end{tabular}

testimonios y plantear hipótesis sobre su procedencia.

7. En cursiva señalamos los desarrollos de las abreviaturas originales: por ejemplo, en este caso, en el códice de Vivar se lee "xtianas".

8. Señalamos entre corchetes aquellos pasajes que, por la cuestión de encuadernación antes mencionada, son hoy en día ilegibles. Su interés no es, evidentemente, ecdótico, pero consideramos que debemos indicarlos en nuestra transcripción de las lecturas que cotejamos. 


\begin{tabular}{|c|c|c|c|c|}
\hline V. & $\mathrm{V}$ & $R$ & $T$ & $C$ \\
\hline 84 & $\begin{array}{l}\text { Fer lo he amidos, de } \\
\text { grado non aurie nada }\end{array}$ & $\begin{array}{l}\text { Ca en pavor de los } \\
\text { omes de grado non } \\
\text { aurie nada }\end{array}$ & $\begin{array}{l}\text { Ferlo e amidos, de } \\
\text { grado non avrie } \\
\text { nada }\end{array}$ & $\begin{array}{l}\text { Fer lo e amidos, } \\
\text { de grado non abrie } \\
\text { nada }\end{array}$ \\
\hline 123 & $\begin{array}{l}\text { Nos huebos auemos } \\
\text { en todo de ganar } \\
\text { algo }\end{array}$ & $\begin{array}{l}\text { Nos amos auemos } \\
\text { ento de ganar algo }\end{array}$ & $\begin{array}{l}\text { Nos huebos } \\
\text { avemos entodo de } \\
\text { ganar algo }\end{array}$ & $\begin{array}{l}\text { nos huebos auemos } \\
\text { en todo de ganar } \\
\text { algo }\end{array}$ \\
\hline 138 & $\begin{array}{l}\text { Huebos auemos } \\
\text { que nos dedes los } \\
\text { marchos }\end{array}$ & $\begin{array}{l}\text { amos auemos } \\
\text { que nos dedes los } \\
\text { mantos }\end{array}$ & $\begin{array}{l}\text { huebos avemos } \\
\text { que nos dedes los } \\
\text { marcos }\end{array}$ & $\begin{array}{l}\text { huebos auemos } \\
\text { que nos dedes los } \\
\text { marchos }\end{array}$ \\
\hline 173 & $\begin{array}{l}\text { Ca mientra que } \\
\text { visquiessen refechos } \\
\text { era } n \text { amos. }\end{array}$ & $\begin{array}{l}\text { ca mientras que } \\
\text { visquiesen ricos } \\
\text { eran amos }\end{array}$ & $\begin{array}{l}\text { Ca mientra } \\
\text { que visquiesen } \\
\text { rehechos eran } \\
\text { amos }\end{array}$ & $\begin{array}{l}\text { ca mientra que } \\
\text { visquiesen Reechos } \\
\text { eran amos }\end{array}$ \\
\hline
\end{tabular}

Como puede comprobarse, resultaría imposible que las lecturas divergentes de $T$ y $C$ con respecto a $R$ coincidiesen entre ambas como resultado de muy numerosas actualizaciones poligenéticas por conjetura de copista. Tampoco tendría sentido que, de forma independiente, los copistas de $T$ y $C$ realizasen dichas correcciones sobre lo que leen en $R$, dando como resultado lecturas casualmente idénticas a las de $V$, de las que resultan divergentes las de $R$.

Por tanto, a la luz de estos datos, nuestra hipótesis es que $R$ no puede constituir el antecedente inmediato de $T$ y $C$, siendo el manuscrito que estos copian. Ni en $T$ ni en $C$ se transmiten ninguno de los muchos errores separativos de $R$ con respecto a $V$. Más bien, estos errores se deben a múltiples circunstancias, que pasaremos a comentar.

Nótese, como punto de partida, cómo $R$ presenta un íncipit centrado en describir las características del texto que copia (su contenido está conformado solo por "versos»), así como la naturaleza del documento (un pergamino) y sus circunstancias materiales: esto es, su falta de hojas y, por tanto, la naturaleza incompleta del texto origen. Por su parte, los íncipits de $T$ y $C$ coinciden casi por completo entre sí, fuera de variantes en enlaces preposicionales ("del/de la») o sintagmas ("el que sigue/el siguiente») que no tienen valor diferenciativo; con respecto a $R$, son muy similares, pero con diferencias reseñables.

A primera vista, parece evidente que $R$ está copiando directamente sobre el códice $V$ de Vivar, mientras que la coincidencia entre $T$ y $C$ nos puede llevar a pensar en un subarquetipo común o en que uno copia a otro. Por el momento, esta cuestión queda abierta hasta el planteamiento de nuestro estema, donde propondremos una solución. En todo caso, resulta de nuevo evidente que $T$ y $C$ no pueden derivar de $R$ si ambos plantean de forma poligenética un íncipit casi idéntico, y a su vez divergente con respecto al de $R$. 
Es destacable, por otra parte, la marcada voluntad arcaizante del copista de $R$. Prefiere emplear el posesivo "nueso» o el causal "ca» en "Ca asi», en lugar de "que asi»; utiliza "exir» por «Sacar», "colar» por «abrir», «toller» por "ganar», «erguir» por «tornar», "Otear» por «ver». Al mismo tiempo, actualiza el léxico en otras ocasiones: "parar» por "posar», «refechos» por «ricos». Parece, por una parte, que intenta darle al texto una pátina de mayor antigüedad, por motivos que no hemos podido esclarecer. Cuando quiere «envejecer» la copia, recurre a términos que conoce del vocabulario medieval, pero por lo general los usa de forma incorrecta: véase, por ejemplo, «exir», que significa "Salir», y así lo emplea correctamente en "exio por la puerta e en Arlançon pasaua"; pero no en "exio el pie del estribera mal ferida daba"?.

Nótese también que desconoce por completo el significado de «huebos» como «necesidad», lo que le lleva a adoptar diferentes medidas de actualización del término. Con propósito arcaizante, al no entender "huebos me serie» como «me haría falta ${ }^{10}$, solo se le ocurre facilitar la lectura por "mas mancarie», acentuando el daño que causa la pobreza del Cid a su compañía (el verso anterior en $V$ es «bien lo vedes que yo no trayo auer»). Lo sustituye por "amos», término que sabe leer correctamente como "ambos", y que tendría sentido en las modificaciones realizadas: "nos amos auemos ento de ganar algo" (nótese también la apócope de «-do») y "amos auemos que nos dedes los mantos".

El copista de $R$, por tanto, no siempre entiende el texto. Se aprecia esto en cómo sustituye "una feridal» por "mal ferida", tal vez porque no entiende "herida" como "golpe»; una acción, no su resultado. En el sintagma "en la glera posaua", sustituye el verbo por "parava" para evitar la repetición con el verso anterior, en un caso de ultracorrección: «Salio por la puerta, en arlançon posaua». Cuando Rachel y Vidas aceptan pagar los seiscientos marcos, el copista de $R$ confunde la intervención posterior de Martín Antolínez, "Ya vedes que entra la noch, el Çid es presurado/huebos auemos que nos dedes los marchos" por una petición de los prestamistas judíos: así, se entiende que copie "amos» en lugar de «huebos", poniendo en boca de ambos personajes la posterior solicitud de «mantos» en lugar de "marchos", pues seguramente confunda el dinero con los ropajes que Rachel y Vidas acabarán recibiendo más adelante. El cambio en el verso «non le osarien uender al menos dinarada", donde se sustituye el sintagma "al menos dinarada" por «nin menos dinerada», también es fruto de una confusión. En el caso de

9. Estas lecturas incorrectas pueden relacionarse con el empleo de la "fabla antigua" como recurso lingüístico arcaizante en el romancero nuevo y la comedia de finales del siglo XVI. Esta cuestión daría pie a un estudio más específico sobre esta cuestión, que no podemos tratar en este artículo. Véanse a este respecto los trabajos ya clásicos de ZAmora Vicente (1983) y SALVAdor Plans (1992). Cabe también la posibilidad de que el empleo común de "exir» como "salir" y "sacar" por parte del copista responda a un uso dialectal de ambos verbos como sinónimos, lo que le lleva, en su empeño arcaizante, a buscar un verbo medieval común a los dos significados. Pero esto es solo una conjetura, que simplemente proponemos como aproximación a esta cuestión.

10. Véase Montaner (2007: 69, v. 83). 
«Compañas» en lugar de "gentes», sustituye por un sinónimo tal vez por confusión entre las "yentes xpistianas», el pueblo burgalés, y los hombres del Cid, su compañía militar. Comete un error de lectura en "Espeso e el oro", donde "espeso» es el perfecto de «espender», que significa "gastar»" ${ }^{11}$ puesto que lo sustituye por «el peso», podría explicarse por confusión de la grafía «» en "efpeso» por «", lo que deriva, en un caso de lectio facilior, a "el peso" ${ }^{12}$. Tampoco entiende "Fer lo he amidos» como una perífrasis de obligación "hacerlo he, amigos»" ${ }^{13}$ de modo que lo cambia por un verso completamente diferente.

Parece quedar anulada toda dependencia de $T$ y $C$ con respecto a $R$, dibujándose así la existencia de dos ramas diferenciadas en el estema: una, con $R$, y otra, con las copias dieciochescas $T$ y $C$. Ahora bien, para determinar la filiación existente entre $T$ y $C$ no podemos cotejar únicamente ambos, puesto que los errores particulares de cada uno no tendrían por sí mismos valor conjuntivo o separativo. Necesitamos, por tanto, compararlos con $V$, para determinar si existió algún antecedente común a ambas copias dieciochescas en el estema, y, de ser así, cuál es la filiación entre todas ellas.

- Errores comunes a $T$ y $C($ con respecto a $V)$ :

\begin{tabular}{|c|c|c|c|c|}
\hline V. & V & $\mathrm{R}$ & $\mathrm{T}$ & C \\
\hline 17 & $\begin{array}{l}\text { Burgeses e } \\
\text { burgesas por } \\
\text { las finestras son } \\
\text { [puestas] }\end{array}$ & $\begin{array}{l}\text { Burgeses e } \\
\text { Burgesas por } \\
\text { las finiestras son } \\
\text { puestas }\end{array}$ & $\begin{array}{l}\text { Burgeses e } \\
\text { Burgesas por } \\
\text { las finiestras son } \\
\text { puestos }\end{array}$ & $\begin{array}{l}\text { Burgeses } \\
\text { eburgesas por } \\
\text { las finiestras son } \\
\text { puestos }\end{array}$ \\
\hline 69 & $\begin{array}{l}\text { Pagos myo çid } \\
\text { el campeador et } \\
\text { todos los otros } \\
\text { queuan aso } \\
\text { çeruicio }\end{array}$ & $\begin{array}{l}\text { Pagos mio cid } \\
\text { campeador e } \\
\text { todos los otros } \\
\text { que van a su } \\
\text { s[ilegible] }\end{array}$ & $\begin{array}{l}\text { Pagos mio cid, e } \\
\text { todos los otros } \\
\text { que van a su } \\
\text { servicio }\end{array}$ & $\begin{array}{l}\text { Pagos mio Çid e } \\
\text { todos los otros } \\
\text { que van a su } \\
\text { seruiçio }\end{array}$ \\
\hline 136 & $\begin{array}{l}\text { Dixo Rachel e } \\
\text { Vidas «dar gelos } \\
\text { de grado" }\end{array}$ & $\begin{array}{l}\text { Dixo Rachel e } \\
\text { Vidas dargelos } \\
\text { hemos de grado }\end{array}$ & $\begin{array}{l}\text { Dixo Rachel } \\
\text { evidas dargelos e } \\
\text { de grado }\end{array}$ & $\begin{array}{l}\text { Dixo Rachel e } \\
\text { Vidas dargelos e } \\
\text { degrado }\end{array}$ \\
\hline
\end{tabular}

11. Véase MONTANER (2007: 69, v. 81).

12. Nótese también que la proximidad del término "oro» validaría la lectura de "peso» en el campo semántico de la economía. Ya en 1246 (fecha más temprana que hemos localizado para este uso) se documenta un anónimo "Acuerdo entre el abad de Irache y Domingo Périz» [Documentos de la Colección Diplomática de Irache, II (1223-1397); consultado en CNDHE, Instituto de Investigación Rafael Lapesa], en el que se declara: «Si aquesta ferme non ualiesse, es fiança don Miguel Angel de C. morabedis alfonsis de oro e de peso. Otrosi Domingo Periz deuant dito dio fermes Pero Uelaz que faga buena esta cequia de todos omnes e de todas las mulieres d'aquest sieglo secundum forum terre. Si aquesta ferme non ualiesse, es fiança Domingo Marco de C. morabedis alfonsis de oro e de peso».

13. Véase MONTANer (2007: 69, v. 84). 
La alternancia entre "puestas» y "puestos» plantea una cuestión muy significativa en la collatio. Menéndez Pidal (1911: 909) señaló en su edición paleográfica del códice de Vivar: "Después de son se añadió de letra posterior y más chica puestas; estaba casi ilegible, pero con reactivo leí clara la $a$; con tinta posterior, que borré previamente, se había repasado puestos, y así leyeron Ulibarri y los editores». Debido a la intervención con reactivos, no podemos comprobar tales cambios en el códice más allá del testimonio de Menéndez Pidal. Esto implicaría que $R$ constituyese un punto intermedio entre la adición de "puestas" y su conversión en "puestos", siendo esta última lectura la que recogen $T$ y $C$ puesto que sería la versión legible en el códice en el siglo XviII; lo que haría a $R$ un manuscrito anterior a Ulibarri.

Sin embargo, pese a lo indicado por Menéndez Pidal, ni Ulibarri ni todos los editores modernos leen "puestos»: Ulibarri mantiene "puestas» (f. 1v.), sin que Pellicer anote nada al respecto, y esta lectura también la recoge Sánchez (1779: 231). Esto último es especialmente significativo ${ }^{14}$. Esto implica, por un lado, dos opciones con respecto a la lectura común y separativa de $T$ y $C$ ("puestos»): o bien ambos proceden de un subarquetipo común, copiado con posterioridad al cambio en "puestos» en el códice (lo que implicaría que derivaría directamente de este), o bien en $T$ y $C$ se realiza una modificación poligenética, una actualización ${ }^{15}$ que realizan ambos copistas del XVIII. Pero, por otro lado, para resolver esto tendríamos que abordar el problema que plantea cuál sería la lectura que presentaba $V$ en este momento. La cuestión radica en por qué ambos testimonios dieciochescos

14. En el siglo XIX, por el contrario, sí se reproduce la lectura "puestos» en las ediciones posteriores, como la reedición de la de Sánchez realizada por Florencio Janer para la Biblioteca de Autores Españoles en 1864, quien corrige la obra de 1779 «á vista de los codices y manuscritos antiguos»; de hecho, JANER (1864: 1, n. 10) señala que Sánchez edita "puestas", pero, al tener a mano el códice de Vivar, que le presta el marqués de Pidal, puede corregir la lectura ahora por "puestos", lo que demuestra que esta fue la variante legible en el siglo XVIII (lo que hace más confuso que Sánchez escogiera "puestas").

15. En la siguiente nota ahondamos en esta cuestión, siguiendo la norma contenida en la Gramática de 1771. No obstante, la norma era flexible, y así podría entenderse que la lectura en "puestos» es una apreciación propia del siglo XVIII, interpretándose el verso como un caso de silepsis. Esto es, el adjetivo concuerda en masculino plural con los sustantivos a los que acompaña, aunque estos sean uno masculino y otro femenino, porque el hablante concibe ambos como expresión de colectividad y muchedumbre. La silepsis aparece tratada en la Gramática de 1771 (Real Academia, 1771: 345-348), pero interesa especialmente en este caso la aportación de MARTínEz GÓmEZ GAYOSO (consultamos la edición de 1769: 338-339): «Syllepsis, ó Concepcion. Esta Figura se cométe quando lo que falta en la Oracion, se toma de la parte mas cercana, mudando el género, número, y caso, ó alguno de los demas accidentes [...]. Tambien se usa con Nombre colectivo, que significa muchedumbre, y se hace la concordancia en el número plurál: Iba en la Procesion tanta gente, hombres, niños, y muberes: unos pobres, y otros ricos. Aquella palabra gente es el Nombre colectivo». Pueden rastrearse antecedentes a esta postura de Gómez Gayoso en Nebrija y Correas, para quienes, respectivamente, este recurso se produce cuando «con un verbo o nombre adjectivo cogemos cláusulas de diversos numeros, o nombres substantivos de diversos generos, o nombres y pronombres de diversas personas", y "quando se conzibe en la mente xenero, o numero mas prinxipal, con el qual conzertamos, el padre i la madre son virtuosos [...] i quando con nombre que significa muchedumbre, conzertamos pluralmente» (LóPEZ MARTínEZ y HERNÁNDEZ SÁNCHEZ, 1994: 148). 
mantienen la supuesta lectura de la época en el códice, que Menéndez Pidal señaló que era "puestos", pero Sánchez, en el mismo siglo, editó según la lectura "puestas» que solo pudo desvelarse más de un siglo después al aplicarse reactivos sobre el documento. ¿Recogió acaso Sánchez la lectura de Ulibarri, a pesar de que declaró que le parecía una mala copia (Sánchez, 1779: 228-229), pero en este caso consideraba que era una lectura correcta? ${ }^{16}$. Es difícil precisarlo, sobre todo porque los restantes testimonios dieciochescos o anteriores, fuera de $T$ y $C$ (esto es, Sandoval, Berganza, Sarmiento), no transmiten este verso en concreto. Por tanto, no podemos dar una respuesta definitiva que nos permita discernir si $T$ y $C$ modernizan de forma independiente o si ambos proceden de un subarquetipo en el que sí se hubiese transmitido la lectura "puestos», una vez se modificó el códice de Vivar, o bien que en ese subarquetipo se hubiese realizado esa modificación por innovación monogenética. En todo caso, sí podemos datar $R$ en una fecha cercana a la de Ulibarri y necesariamente anterior al cambio por "puestos" efectuado en el códice $V$.

En cuanto a "dargelos e de grado", en $T$ y $C$, la solución en $R$ es diferente por adición de un verbo de obligación en plural («dar gelos hemos de grado») que, además, completa la medida octosilábica del verso; frente a esto, encontramos el verbo de obligación en singular «e», que también es una adición con respecto a $V$.

Por el contrario, la variante restante merece un comentario más detallado. La eliminación del apelativo "campeador" en "pagos mio cid campeador" en $T$ y $C$ no puede explicarse a la vista de $R$, puesto que en este se mantiene la lectura del verso hipermétrico de $V$ (Montaner, 2011: 564). Tal vez esta cuestión métrica justifique tal elipsis, pero no lo podemos justificar con certeza. En todo caso, quedaría por discernir si se trata de una modificación monogenética a un testimonio anterior y común a $T$ y $C$ (el mencionado subarquetipo del que derivarían ambos) o a una solución poligenética a ambos testimonios. Es un cambio significativo, no trivial, que, por su duplicidad en dos testimonios independientes, por sí solo refuerza la idea del subarquetipo común. Pero, puesto que se trata de un único error común, es cuantitativamente insuficiente como para determinar si se trata de una lección equipolente o adiáfora, por lo que esta cuestión precisa aún de una conclusión determinante. Volveremos a ella más adelante.

16. Aceptando que ya en 1779 en el códice $V$ se leería "puestas" (y así lo podemos deducir de la corrección de Janer en 1864), Sánchez podría estar siguiendo la norma de la Gramática de 1771 (Real Academia, 1771: 323): "Quando hay dos sustantivos en plural con un solo adjetivo debe este concertar con el último, y así se dice: las esperanzas y temores eran vanos: sus temores y esperanzas eran vanas; y si se coloca el adjetivo ántes de los sustantivos, se concierta con el mas cercano, como: eran vanos sus temores y esperanzas: eran vanas sus esperanzas y temores». En el caso de "burgueses e burguesas", el adjetivo más correcto, según esta norma, es "puestas», que concuerda con el femenino plural del último sustantivo. 
- Errores comunes a $R$ y $T$ :

\begin{tabular}{|c|l|l|l|l|}
\hline V. & \multicolumn{1}{|c|}{$V$} & \multicolumn{1}{c|}{$R$} & \multicolumn{1}{c|}{$T$} & \multicolumn{1}{c|}{$C$} \\
\hline 96 & $\begin{array}{l}\text { Martin antolinez } \\
\text { non lo de tarua }\end{array}$ & $\begin{array}{l}\text { Martin antolinez } \\
\text { non lo detardaua }\end{array}$ & $\begin{array}{l}\text { Martin Antolinez } \\
\text { non lo detardaba }\end{array}$ & $\begin{array}{l}\text { Martin Antolinez } \\
\text { non lo detarua }\end{array}$ \\
\hline 169 & $\begin{array}{l}\text { Ca amouer a myo } \\
\text { çid }\end{array}$ & $\begin{array}{l}\text { Ca mouera mio } \\
\text { çid }\end{array}$ & $\begin{array}{l}\text { Ca mover a mio } \\
\text { Cid }\end{array}$ & $\begin{array}{l}\text { Ca amouer a mio } \\
\text { Cid }\end{array}$ \\
\hline 196 & .x.x.x marchos & Treynta marcos & Treinta marcos & xxx. marcos \\
\hline
\end{tabular}

La collatio también debe realizarse por separado entre $R$ y cada uno de los dos testimonios dieciochescos ( $T$ y $C$ ) que supuestamente derivan de él, para confirmar o cuestionar nuestra hipótesis de que estos últimos no proceden de aquel.

Algunos de los errores comunes a $R$ y $T$ pueden atribuirse a despistes de copista, con base poligenética, y por tanto plausibles en dos espacios temporales de copia alejados cronológicamente. Entre ellos hemos localizado abreviaturas no desarrolladas y numerosas actualizaciones que podrían constituir actividades comunes (lectio facilior) al copista del siglo XVI-XVII y a Trigueros.

Sin embargo, otros errores conjuntivos entre $R$ y $T$, que señalamos en el cuadro anterior, sí son susceptibles de constituir variantes separativas con respecto a $V$ y $C$. Aun así, son tan escasos que no podemos establecer un patrón sobre el que plantear una hipótesis de una rama común a ambos. Igualmente, podemos justificarlos como variantes equipolentes. Si en $V / C$ se utiliza "detarua», en perfecto simple, los copistas de $R / T$ prefieren "detardaba", en imperfecto, para hacer coincidir el tiempo verbal, así como la rima, con el verso siguiente: "Por Rachel et Vidas apriessa demandaua». Lo consideramos una lectio facilior poligenética para restituir una haplografía presente en el original (Montaner, 2001: 565). Esto se une a otro error de copia bastante significativo, como es la elipsis de uno o dos versos completos en $R / T$ :

\begin{tabular}{|c|c|c|c|c|}
\hline VV. & $V$ & $R$ & $T$ & $C$ \\
\hline $97-99$ & $\begin{array}{l}\text { Por Rachel e vidas } \\
\text { apriessa demandaua. } \\
\text { / Passo por burgos, al } \\
\text { castiello entraua, / Por } \\
\text { Rachel e vidas apriessa } \\
\text { demandaua. }\end{array}$ & $\begin{array}{l}\text { Paso por } \\
\text { burgos al } \\
\text { castiello } \\
\text { entraua / } \\
\text { por Rachel e } \\
\text { Vidas a priesa } \\
\text { demandaua }\end{array}$ & $\begin{array}{l}\text { Por Rachel e } \\
\text { Vidas apriesa } \\
\text { demandaba. }\end{array}$ & $\begin{array}{l}\text { Por Rachel e Vidas } \\
\text { apriesa demandaua } \\
\text { / paso por burgos } \\
\text { al castiello entraba. } \\
\text { / por Rachel e } \\
\text { Vidas apriesa } \\
\text { demandaua }\end{array}$ \\
\hline
\end{tabular}

La evidente repetición del verso «Por Rachel e Vidas apriessa demandaua» en $V$ se transmite sin ninguna modificación en $C$. Sin embargo, el copista de $R$ y Trigueros en $T$ toman posturas diferentes frente a la repetición. $R$ elimina el primer verso. En $T$, además, se produce otra supresión, esta vez sin motivo aparente, del verso "Passo 
por Burgos, al castiello entrauan: Trigueros, en su empeño por corregir y por tanto eliminar el otro verso repetido, también elide por equivocación el verso intermedio.

La aféresis en "mover», en $R / T$, frente a "amouer», en $V / C$, se explica por percepción de cacofonía o de una duplografía entre la partícula "ca» y la «a-» que inicia el verbo: en $R / T$, por tanto, se ultracorrige la lectura. Por último, el desarrollo de la cifra en números romanos por un número cardinal no constituye ni error ni variante significativa; sin embargo, sí es una decisión de copista a la que volveremos a continuación, pues parece marcar una tendencia que, junto a otras lecturas semejantes, sí puede establecer un patrón con carácter separativo.

- Errores comunes a $R$ y $C$ :

\begin{tabular}{|c|l|l|l|l|}
\hline V. & \multicolumn{1}{|c|}{$V$} & \multicolumn{1}{c|}{$R$} & \multicolumn{1}{c|}{$T$} & \multicolumn{1}{c|}{$C$} \\
\hline 16 & $\begin{array}{l}\text { Lx. pendones } \\
\text { leuaua }\end{array}$ & $\begin{array}{l}\text { nuebe pendones } \\
\text { leuaua }\end{array}$ & $\begin{array}{l}\text { sesenta pendones } \\
\text { lebaba }\end{array}$ & $\begin{array}{l}\text { Ix pendones } \\
\text { leuaba. }\end{array}$ \\
\hline 167 & $\begin{array}{l}\text { poned las en } \\
\text { umestro saluo }\end{array}$ & $\begin{array}{l}\text { poneldas en vueso } \\
\text { sa[ilegible] }\end{array}$ & $\begin{array}{l}\text { ponedlas en } \\
\text { vuestro salvo }\end{array}$ & $\begin{array}{l}\text { poneldas en vro } \\
\text { saluo }\end{array}$ \\
\hline
\end{tabular}

Los errores comunes a $R$ y $C$ deben ser tratados con cautela. En primer lugar, no son suficientes cuantitativamente como para sostener que son conjuntivos, y que marquen así una rama separativa frente a los otros testimonios. Por otra, las conclusiones que extraemos de su análisis van en otra dirección: en la confirmación de que $R$ forma una rama separativa con respecto a $T$ y $C$.

La variación entre "ponedlas" y "poneldas" es solo un caso de metátesis que, si $R$ fuese la fuente de $T$ y $C$, se transmitiría a ambos, pero Trigueros la corregiría (coincidiendo así con la lectura correcta del original $V$ ), no así en $C$. Por el contrario, debería entenderse como que un modelo común a los tres presentaría tal metátesis, que Trigueros enmendaría.

Pero el error en el número de pendones es definitivamente más importante, y termina de orientar nuestra hipótesis del subarquetipo común. Antes señalamos un caso en el que $R$ y $T$ leen como ordinal un número romano. Con solo una muestra, podría interpretarse como un caso en el que la opción de $C$, de mantener el número romano, casualmente coincidiese con $V$, pero sin que esto implicase una divergencia significativa con respecto a $R$ y $T$. Sin embargo, en las lecturas numéricas de "pendones" nos encontramos con un caso totalmente distinto. Por una parte, confirma la tendencia de $C$ a escribir en números romanos, pero hace menos casual que sea otra coincidencia poligenética con $V$. Por otra, las divergencias numéricas en las lecturas de los cuatro testimonios son evidentes y orientan nuestras hipótesis de ramas separativas.

$R$ lee erróneamente "Lx" como "nuebe». Esto impide cualquier relación de este con $T$ : no es posible que la lectura "sesenta" de $T$, en número ordinal, pueda derivar de "nuebe» en $R$, también ordinal. Tampoco lo podemos entender como un 
caso de contaminación: según el estema que estamos consultando, por el que $T$ deriva de $R$ y este de $V$, Trigueros no pudo corregir la lectura de "nuebe» por "sesenta» con la lectura del códice de Vivar, "Lx", ya que este erudito ilustrado nunca llegó a manejarlo. En $C$, «IX» sí sigue la lectura de $R$, pero resulta llamativo que sea en números romanos, lo que implicaría la improbable situación de que vuelve a seguir, supuestamente por poligénesis, la misma tendencia que en $V$.

- Errores exclusivos de T:

\begin{tabular}{|l|l|c|l|}
\hline Grandes aueres & Grandes aueres & Munchos aueres & Grandes aueres \\
\hline $\begin{array}{l}\text { Gradanse Rachel } \\
\text { e vidas con aueres } \\
\text { monedados }\end{array}$ & $\begin{array}{l}\text { Gradanse Rachel e } \\
\text { Vidas con aueres } \\
\text { monedados }\end{array}$ & - & $\begin{array}{l}\text { Gradanse Rachel e } \\
\text { Vidas con aueres } \\
\text { monedados }\end{array}$ \\
\hline
\end{tabular}

Por último, los errores localizados solo en $T$ se explican como producidos por malas lecturas o copias apresuradas de Trigueros. Recordemos que el manuscrito de la Disertación estuvo pensado para su lectura pública, lo que justificaría una redacción rápida, sobre la que Trigueros llegó a realizar enmiendas y correcciones, aunque su ánimo fuese "conservar un fragmento a mi parecer de los más antiguos de nuestra poesia» (1766: f. 63r.).

Por lo general, son errores producidos por elipsis, lectiones faciliores en actualización de conjunciones o reajuste de la concordancia de número entre verbo y atributo. Son errores no significativos, erratas que no merece la pena comentar, puesto que no aportan nada a la collatio. Más interesantes son otros dos casos, que son los que aportamos en el cuadro anterior. Por claro despiste elide todo el verso "Gradanse Rachel e Vidas con aueres monedados". No obstante, no encontramos ninguna explicación plausible a la variante "munchos" de $T$ frente a "grandes" del resto de los testimonios. De tratarse de una actualización efectuada por Trigueros, habría optado por la forma «muchos», en vez de un aparente arcaísmo con «-n-», que es la solución que escoge y que tal vez le parece más coherente que "grandes", en su valor cuantificativo de los «aueres». Esta excepción puede ponerse en el mismo ámbito que otras variantes de copia que apreciamos en un texto posterior de Trigueros: en sus Poesías filosóficas, en 1775, vuelve a copiar los versos del Cantar, remitiendo a la Disertación. La muestra es muy breve (solo los diez versos iniciales; podríamos denominarla T2), y por tanto insuficiente como para establecer conclusiones. Sin embargo, se aprecian variantes que debemos comentar.

\begin{tabular}{|l|l|}
\hline \multicolumn{1}{|c|}{ DISERTACIÓN (1767) } & \multicolumn{1}{c|}{ POESÍAS FILOSÓFICAS (1775) } \\
\hline tan fuertemente lorando & fuertemiente \\
\hline Y uzos sin cannados & E uzos \\
\hline Et sin falcones & E sin falcones \\
\hline
\end{tabular}




\begin{tabular}{|l|l|}
\hline \multicolumn{1}{|c|}{ DISERTACIÓN (1767) } & \multicolumn{1}{c|}{ POESÍAS FILOSÓFICAS (1775) } \\
\hline ca mucho avie grandes cuidados & grand cuidado \\
\hline Fablo mio Cid & Fablo mio Sennor Cid \\
\hline Que estas en alto & Que, y estas en alto \\
\hline E entrando a Burgos & Et entrando \\
\hline
\end{tabular}

Las variantes «y/e/et» no son significativas. Por el contrario, "fuertemiente» se acerca más al "fuertemientre» del códice $V$; mientras, las copias $R, T$ y $V$ optaron por "fuertemente», como ya vimos. Cambia de plural a singular en "grand cuidado", lo que podría explicarse como una modificación arcaizante que, a su vez, convierte el verso eneasílabo en octosílabo. La adición del apelativo "sennor" completa la medida octosilábica del verso, aunque sea una lectura ausente del resto de testimonios. Lo mismo ocurre con el adverbio "y», que no se trataría de una adición errónea de Trigueros, puesto que interpreta el verso en nota al pie como "Que estas ay en lo alto, en el Cielo»; no obstante, este adverbio no se encuentra en ninguno de los testimonios restantes, ni siquiera en $V$; al añadir este adverbio, Trigueros no solo refuerza su antigüedad, sino que también ajusta la métrica.

Es difícil precisar si Trigueros, al redactar sus Poesías filosóficas, vuelve a copiar estos diez versos a partir del manuscrito "del siglo 1500" sobre el que realizó su Disertación, o si emplea la Disertación. Solo indica a este respecto:

Presentè algunos años hace a nuestra Academia una copia de este MS. [el Cantar] que poseo manco al principio, y fin, y mui poco correcto, para que sirviese de Apéndice à mi Disertacion sobre la Rima, y el verso suelto, ó blanco; mas por si Vm. no la tiene presente le copiarè aqui el principio, y en èl verà Vm. ser quasi todos Pentàmetros.

Por tanto, las alteraciones apreciables en estos diez versos podrían deberse a un empeño de Trigueros por ajustar su medida a la de los "pentámetros", o versos alejandrinos (según los define), que constituyen su foco de atención. Puesto que hemos comprobado que Trigueros, pese a declarar que solo transcribiría el texto en $T$, realiza modificaciones en él para modernizarlo, en las Poesías filosóficas, por el contrario, podría interpretarse que envejece el texto para ajustarlo a los objetivos de su ensayo sobre la métrica de la poesía medieval.

- Otros resultados de la collatio:

No mostramos los errores exclusivos de $C$ con respecto a $V$, puesto que no son errores comunes ni lecciones equipolentes, sino erratas de copia. Igualmente, son muy pocas. Pero sí debemos mencionar aparte el tratamiento que cada copista realiza de las abreviaturas del códice original ${ }^{17}$ :

17. Puesto que en este caso solo nos interesa comentar específicamente las abreviaturas, no en su contexto del verso, no indicamos en este caso el número del verso correspondiente. 
ALBERTO ESCALANTE VARONA

CALAS CRÍTICAS EN LA TRANSMISIÓN MANUSCRITA DEL CANTAR DE MIO CID A PARTIR DE SUS COPIAS DIECIOCHESCAS

\begin{tabular}{|l|l|l|l|}
\hline \multicolumn{1}{|c|}{$V$} & \multicolumn{1}{c|}{$R$} & \multicolumn{1}{c|}{$C$} \\
\hline Somos de tierra & tierra & tierra & tra \\
\hline Con uuestro consego & Con uesso consello & Con vuestro consejo & Con uro consejo \\
\hline Uuestra mano & En vuessa mano & Vuestra mano & En vra mano \\
\hline Uuestro saluo & Ueso saluo & Vuestro salvo & En vro saluo \\
\hline Quando atierra & Quando a tierra & Quando a trà & Quando atrá \\
\hline Uuestro saluo & Vueso saluo & vro saluo & Vro saluo \\
\hline Uuestra uentura & Vuesa ventura & Vuestra ventura & Vra ventura \\
\hline Uuestras ganançias & Vuesas ganançias & Vuestras ganancias & Vras ganançias \\
\hline Uuestra mano & Buesa mano & Vra mano & Vra mano \\
\hline Ya me exco de tierra & Ya me exo de tierra & Ya me exio de tierra & Ya me exto de tra \\
\hline
\end{tabular}

En el caso de "tierra", es evidente que el copista de $C$ o bien no sabe leer algunas abreviaturas (aunque sí suele desarrollar la correspondiente a "cristianos", como ya hemos visto), o bien que es muy conservador y mantiene la lectura abreviada del original (que debemos determinar cuál es). Así, por ejemplo, mantiene la abreviatura "trra" o "tra" que parte del códice $V$ y que $R$ y $T$ desarrollan sin mayor problema, si bien Trigueros la mantiene en una ocasión ("Quando a trà"). Más interesante resulta la abreviaura «Vro/vra». Apreciamos cómo en C es sistemático su mantenimiento. Por una parte, debe tenerse en cuenta que esta abreviatura seguía utilizándose en el siglo XVIII, como queda registrado en numerosos apuntes teatrales y otros documentos de la época (por lo que el copista de $C$ actuaría con voluntad conservadora de forma coherente, sabiendo que sus lectores coetáneos podrían leer correctamente estas abreviaturas). Por otra, nótese cómo las soluciones de $R$ responden al carácter arcaizante de su copista, como ya hemos comentado.

\section{STEMMA CODICUM: PROPUESTA DE ESTEMA}

A la luz del análisis realizado, consideramos que el estema cidiano, en su transmisión en los siglos XV-XVIII, sería el siguiente: 


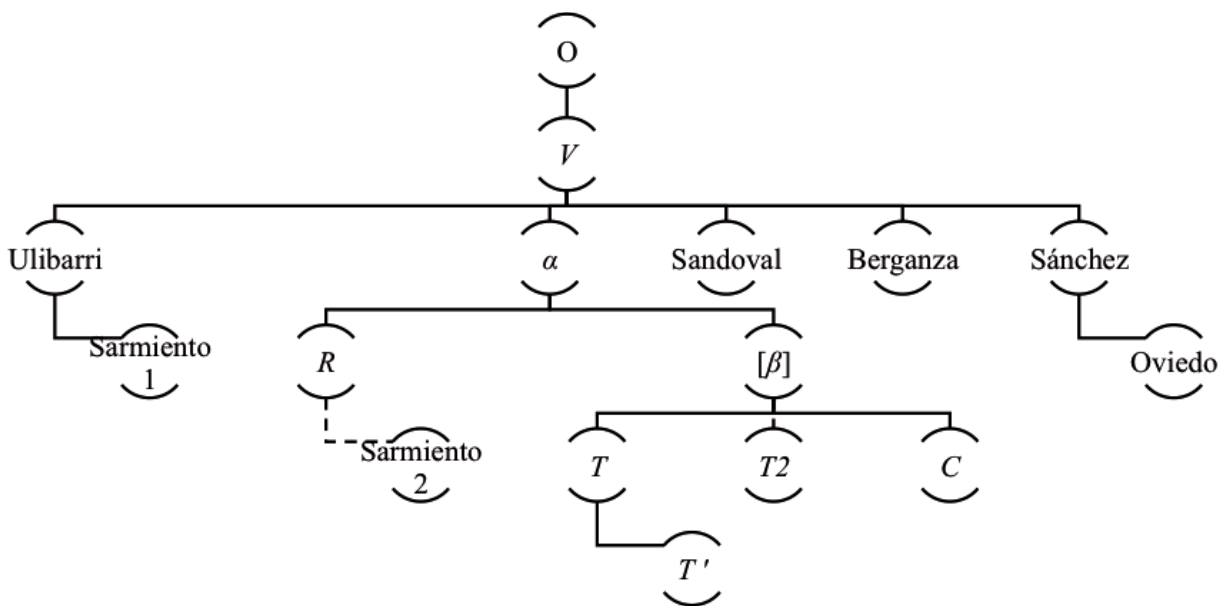

En el caso de las copias dieciochescas que hemos cotejado, el estema sería el siguiente:

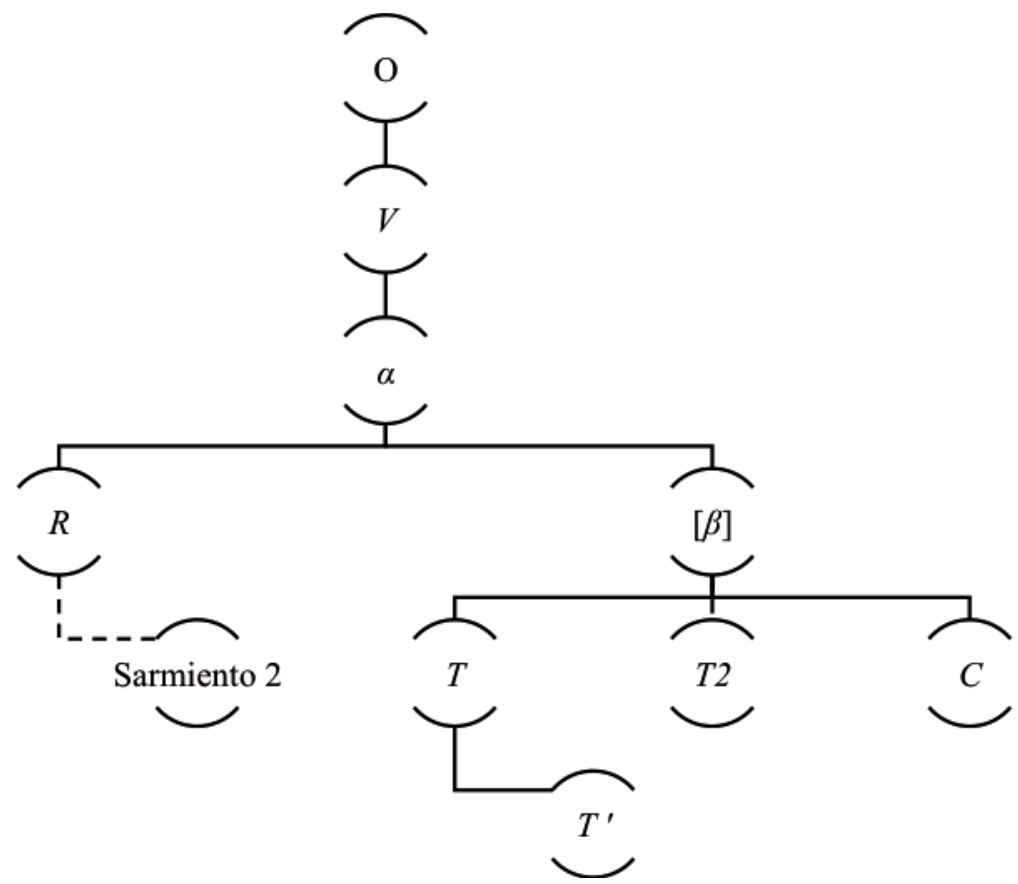


El amplio listado de errores significativos y separativos que hemos elaborado tras el cotejo nos lleva a proponer que $R$ no es el manuscrito base para $T$ y $C$. Por tanto, $R$ no sería el manuscrito de "principios del siglo 1500» que posee Trigueros ${ }^{18}$. Suponemos, por tanto, que existió un manuscrito, hoy perdido: un subarquetipo $\alpha$ en nuestro estema. Esto nos parece, de entrada, la solución para explicar todas las lecturas coincidentes localizadas entre los manuscritos $R, T$ y $C$ que contienen únicamente los primeros 197 versos del Cantar; lecturas a su vez divergentes con respecto a $V$. Todos ellos, atendiendo a esta circunstancia, deben incluirse en la misma rama del estema. Por otra parte, las lecciones adiáforas entre $R$ y $T / C$ refuerzan esta hipótesis. Pero sus relaciones entre ellos son más complejas de lo que se creía hasta ahora, de modo que tendremos que trazarlas a partir del cruce entre los datos cronológicos de cada testimonio y la filiación de sus errores.

Ulibarri indicó que en 1596 el códice ya se encontraba en Vivar. Montaner (2011: CCXCVI-CCXCVII) sugiere que antes de 1512 podría haberse trasladado ya desde la biblioteca del monasterio de San Pedro de Cardeña hasta la escribanía del Concejo de Vivar, lo que coincidiría con la fecha supuesta por Trigueros para el "traslado", el facticio manuscrito que tiene en su poder y en el que se localizan los versos que copia y comenta en la Disertación. La copia $R$, por lo que se indica en su íncipit, se realizó cuando $V$ ya estaba en Vivar. Además, el copista de R nos está dando importante información material sobre $V$ (y, quizá, sobre $\alpha$ ). Nos indica que al manuscrito que está copiando le «faltan muchas hojas y lo q se halla es desde el destierro", y que contiene los "versos de la Historia del Çid Ruidiaz Campeador sacados de un libro antiguo escripto en pergamino que el concejo de Vivar tiene en sus Archivos». Claramente, $R$ está describiendo el manuscrito $V$, que contiene el Cantar, pero no la historia completa del Cid. Ya en el siglo XVIII resultaba evidente para copistas y eruditos que al Cantar le faltaba buena parte del relato del héroe burgalés: así lo expresó Sánchez (1779: 221), quien notó la supresión de hojas en el códice, y Janer (1864: XVIII-XIX) ${ }^{19}$, quien destacó cómo las crónicas medievales del Cid probaban la existencia de más materiales narrativos anteriores al episodio del destierro. Nótese también que Trigueros, cuando en sus Poesías filosóficas describe el manuscrito que posee y por el que ha conocido los versos del Cantar, indica que está "manco al principio, y fin»: Trigueros conoce la historia del Cid, no el códice de Vivar, pero aun así identifica que el fragmento que está copiando está

18. Por otra parte, Trigueros indicó que el manuscrito estaba incluido en "un tomo en quarto", mientras que el manuscrito $\mathrm{R}$ tiene tamaño de folio.

19. Léase: «Las repetidas alusiones que en las primitivas crónicas generales se hacen á los poetas ó juglares del Cid en la primera época de sus hazañas, ántes de salir del reino en desgracia del monarca, probarían nuestro aserto, si no lo probase, sin género alguno de duda, la misma Crónica del Cid, cuyo contexto con el Poema se puede observar repetidas veces. [...] Ademas la Crónica conserva los mismos asonantes del Poema, prueba clara de que el cronista tuvo presentes los cantares. [...] El asunto del Poema, reducido tal como hoy se encuentra, comienza desde la mitad del capitulo xci de la Crónica, faltando, por lo mismo, la narración de todo lo anterior». 
incompleto; no ya el códice $V$, que no ha podido ver, sino el texto en sí, la narración trunca del destierro del Cid.

Efectivamente, esto es lo que se expone en el íncipit de $R:$ «[...] lo que se halla es desde el destierro»; igualmente, su copista es consciente de que lo que está copiando corresponde a un relato épico más extenso, cuando hace referencia a que «Hizieron hazer esta Historia en el verso q entonces se usaba los Reyes nietos del çid»; dato genealógico que se menciona en los últimos versos del Cantar (v. 3724), pero también en la Cronica de 1512, que supuso uno de los medios de mayor transmisión de la leyenda (véase Cronica [...], 1512: ff. CIIIr.-CXIIIv. donde se lista la genealogía real que desciende del Cid; o 1512: f. XCIIr. donde se indica que el nieto del Cid fue rey de Navarra).

No obstante, $R$ no copiaría directamente sobre $V$, sino sobre el subarquetipo intermedio $\alpha$, tal y como hemos propuesto. Lo que nos lleva a analizar los íncipit de $R, T$ y $C$ : porque, puesto que $R$ está copiando el contenido de $\alpha$, hay que discernir si esto implica que también reproduce literalmente su íncipit, al que no podemos acceder puesto que $\alpha$ se ha perdido. Los datos del íncipit de $R$ revelan que $\alpha$ tuvo que copiarse sobre la lectura directa del códice $V$, lo que explica que el copista de $R$ pueda describirlo con detalle a pesar de que no lo haya visto: indica la ausencia de hojas, el soporte de escritura, la localización geográfica del volumen y el carácter incompleto de su narración. Todos estos datos debieron figurar, pues, en el íncipit original de $\alpha$, y se transmitieron consecutivamente a $R, T$ y $C$ : ninguno de los tres consultó directamente $V$, pero los datos descriptivos de estos íncipits con respecto al estado de $V$ coinciden con exactitud.

Por consiguiente, y anulada toda dependencia de $T / C$ hacia $R$, como ya hemos explicado, debemos discernir cuál de los dos íncipits conservados constituye el que figura en el perdido de $\alpha$ (recordemos que las diferencias entre los de $T$ y $C$ son mínimas y no significativas, pero que estos a su vez varían notablemente del de $R)^{20}$.

La cuestión radica en el grado de fidelidad de cada copista con respecto al subarquetipo que copia. Sabemos que el de $R$ no duda en alterar el texto para potenciar sus rasgos arcaizantes, mientras que el de $C$ es más conservador, y que $T$, aunque pretenda ser fiel al original, comete varias modificaciones importantes. Además, el nivel de detalle descriptivo de $R$ con respecto a las características materiales y contenidos narrativos de $V$ supera a lo que se recoge en los íncipit de $T$ y $C$, donde no se indica nada de la falta de hojas o de que el «libro antiguo escrito en pergamino" de Vivar solo incluye el relato desde el destierro. Por tanto, si bien estos tres testimonios derivan de $\alpha$, podría interpretarse que el íncipit de

20. $R$ y $T$ presentan algunos errores coincidentes, como ya hemos señalado, pero pueden entenderse como fruto de innovaciones poligenéticas: el modelo de $R, T$ y $C$ sería conservador con respecto a $V$, y así también $\mathrm{C}$, pero Trigueros, y sobre todo el copista de $R$, deciden intervenir sobre las lecturas que realizan de sus respectivos subarquetipos. 
este subarquetipo tenía que ser más cercano al de $R$ que al de $T / C$, más escuetos. Veamos con más detalle esta cuestión.

Queda claro que, a la vista de la materia cidiana conocida en el siglo XVIII, el Cantar resultaba una manifestación incompleta de la leyenda del héroe. No obstante, cabe discutir en qué medida $R$ sería una copia exacta de $\alpha$, desde su íncipit hasta su éxplicit («Solo se saco hasta aqui»). De ser así, estos "versos de la Historia del Cid" serían solo una copia parcial ya desde este primer testimonio subarquetipo. Pero, donde $R$ indica que copia "versos", $T$ y $C$ señalan que son un "traslado". Este es un término que ya desde el siglo XIII se documenta con el significado de "Copia fiel", como fórmula notarial y legal ${ }^{21}$. Evidentemente, $T$ y $C$ son copias fieles de lo que están leyendo: el testimonio parcial de $\alpha$. Y tanto el copista de $R$ como Trigueros son conscientes de que el documento que leen es, a su vez, una transmisión incompleta (en su comienzo y su fin) de ese códice de Vivar que ellos no han conseguido ver: así lo indican ambos en sus éxplicits, y de ahí que en $R$ se indique que se copian "versos» sueltos. Volveremos más adelante sobre este detalle: por el momento, nos interesa señalar cómo esta divergencia entre los íncipits avanza dos aproximaciones diferentes sobre un fragmento de 197 versos que, en todas sus transmisiones tardías, se percibía ya como fragmentario.

Sobre este arquetipo $\alpha$ se producen, en dos ramas diferenciadas, el resto de las copias: por un lado, $R$; por otro, $T$ y $C$. Tras el cotejo, recopilamos diversas pruebas que nos permitirían orientar nuestra reconstrucción de $\alpha$, así como filiar los testimonios $R / T / C$ como derivados de él, mientras que las variantes significativas localizadas son claramente separativas en dos ramas. En primer lugar, la lectura de "Lx pendones", en $V$. Las soluciones divergentes en los tres testimonios pueden explicarse con la existencia de $\alpha$. El copista de $\alpha$ transmitiría correctamente el original "Lx", pero adoptaría una grafía de "L" que la asemejaría a "I», una "l» larga, lo que implicaría el error de $R$, que leería erróneamente "nuebe», y $C$, que copiaría directamente la cifra en numeración romana (ya hemos visto que es un copista conservador en cuanto a abreviaturas y números romanos). $T$, por su parte, leería correctamente $\alpha$. En todo caso, es una lectura separativa de todas las copias. Incluso, si aceptamos la existencia del subarquetipo $\beta$ como origen de $T$ y $C$, como explicaremos más adelante, la transmisión de "Lx" también tendría sentido si en este $\beta$ se mantuviese una grafía confusa, derivada de $\alpha$, y que $T$ leyese como "sesenta» y $C$ como "Ix".

Se explicarían también los errores comunes a $R / T / C$ con respecto a $V$, que ya no serían correcciones sobre la mala copia de $R$ sino derivaciones de un error

21. El testimonio más cercano que hemos podido localizar data de 1251, del anónimo Privilegio que dio el rey don Fernando a Sevilla cuando la ganó (El libro de privilegios de la ciudad de Sevilla). Extraemos este dato del CNDHE (Instituto de Investigación Rafael Lapesa, 2013). El empleo de esta fórmula se extiende a lo largo de la Edad Media y se documenta también en todo el siglo Xvi, decayendo su uso drásticamente en los siglos posteriores. 
común, localizable en $\alpha$. En el arquetipo se leería «fuertemente»frente a «fuertemientre", así como una solución "men/non» frente al original "yo» que ninguno de los tres manuscritos sabría leer correctamente. También encontraríamos en $\alpha$ "amos todos tred al campeador contado", siendo T quien copia mal, leyendo «amos vos traed»: igualmente, $\alpha$, testimonio medieval, copiaría correctamente la forma verbal de $V$ "tred", pero $R$ y $T$ la modernizarían a "traed", mientras que $C$, más conservador, la mantiene. Igual ocurriría con "hinchiremos», que sería la lectura errónea de $\alpha$ frente al "yncamos» de $V$, y que $R$ volvería a copiar erróneamente, como arcaísmo, en "fenchiremos».

Por otra parte, $R$ y $T$ prefieren desarrollar en nombre cardinal las cifras que en el códice $V$, y necesariamente en $\alpha$, aparecen expresadas en números romanos (solución que se respeta en $C$ ). El arquetipo también nos permite explicar las decisiones de cada copista con respecto a las abreviaturas: excluyendo $R$, que es pretendidamente arcaizante, el mantenimiento constante de abreviaturas en $C$ podría explicarse porque, como puede observarse, $\alpha$, cercano cronológicamente a los usos paleográficos de la caligrafía medieval que también se aprecian en $V$, conserva las abreviaturas del códice que copia directamente. Las similitudes entre $V$ y $C$ nos llevan a concluir que $C$ podría tratarse de la copia más cercana al arquetipo $\alpha$ en cuanto a sus lecturas, pese a la distancia temporal entre ambos, y que $\alpha$ se trataría de una copia bastante fiel sobre $V$. En $C$ no se desarrollan las abreviaturas porque está copiando estrictamente a $\alpha$, quien a su vez las mantiene de $V$, y porque el lector dieciochesco podría leer muchas que aún se utilizaban (como «Vro/a»).

En suma, las variantes comunes en $T$ y $C$ frente a $R$ podrían, en su mayoría, explicarse como fruto de la conservación de las alteraciones originadas en $\alpha$ por errores de copia sobre $V$, y que, al trasladarse a $R$, sufrieron modificaciones monogenéticas (arcaizantes en su mayoría) frente a $T$ y $C$, que mantuvieron las lecturas del subarquetipo. Sin embargo, esto no explica algunos casos por los que podríamos plantearnos la existencia de otros subarquetipos. Por un lado, un manuscrito intermedio entre $\alpha$ y $R$ : un subarquetipo de donde procediesen sus múltiples errores de copia. Sin embargo, carecemos de pruebas que nos permitan dar forma a esta posibilidad; igualmente, no resultaría necesario presuponer la existencia de otro subarquetipo en el que relegar la responsabilidad de los errores de copia de $R$, que bien pudieron deberse a los descuidos o intencionalidad (no determinada, como hemos visto) de su escribiente, de modo que no lo incluimos en el estema.

Por otro lado, y más probable, también podríamos suponer que existiese otro subarquetipo común a $T$ y $C$, que los antecediese. Es el subarquetipo beta, $\beta$, que explicaría las tres variantes comunes a ambos testimonios que hemos localizado: 1) el íncipit común; 2) la preferencia por "puestos» en el v. 17; 3) la omisión de "Campeador» en el v. 69. Pero preferimos dejar esta solución como hipótesis. Los argumentos a su favor son relevantes y significativos, si bien son cuantitativamente insuficientes. Estos argumentos plantean también algunas cuestiones críticas, que pasaremos a comentar a continuación: 


\begin{tabular}{|l|l|l|}
\hline \multicolumn{1}{|c|}{$R$} & \multicolumn{1}{|c|}{$T$} & \multicolumn{1}{|c|}{$C$} \\
\hline $\begin{array}{l}\text { Versos de la Historia del Çid Rui } \\
\text { diaz Campeador / sacados de un }\end{array}$ & $\begin{array}{l}\text { Este es un traslado } \\
\text { del Historia del Çid }\end{array}$ & $\begin{array}{l}\text { Este es un traslado } \\
\text { de la Historia del Çid }\end{array}$ \\
libro antiguo escripto en pergamino & Rui Diaz Campeador & Rui Diaz Campeador. \\
que el consejo de viuar tiene en sus & sacado de un libro & sacado de un libro \\
Archiuos / faltan muchas hojas y lo q & antiguo escripto en & antiguo escripto en \\
se halla es desde el destierro / $\sim$ & pergamino que el & pergamino. que el \\
Hizieron hazer esta Historia en el & Concejo de Bibar tiene & Conçejo de Bibar tiene \\
verso q entonces se usaba los Reyes & en sus archivos, el tenor & en sus archivos el tenor \\
nietos del çid $\sim$ & del es el que sigue. & del. es el siguiente. \\
\hline
\end{tabular}

El íncipit común puede ser fruto de ese subarquetipo $\beta$ que ambos copian y que ya deturpase el íncipit de $\alpha$ que pasaría fielmente a $\mathrm{R}$, de forma íntegra. En $\beta$, la información sería menor que en $R$, donde se describía el códice $V$ a través de $\alpha$, interpretando que en él faltaba toda la narración previa al destierro por supresión de hojas. Puesto que en $T$ y $C$ falta esta información, se refuerza la idea de que ambos provengan de un testimonio común, a su vez derivado de $\alpha$. Explica por qué tienen menos información en sus íncipits coincidentes: la supresión de datos solo puede ir en un sentido, y no puede ser casual que se produzca de idéntica forma en dos testimonios (en los que, por otra parte, no hemos localizado rastros de contaminación, aunque son coetáneos).

Aun así, que $\alpha$ fuese ya una copia parcial de los primeros 197 versos del Cantar no implica necesariamente que su íncipit se trasladase directamente a $R$, de manera que en $\beta$ apareciese ya simplificado. Podría ser que el copista de $R$ realmente innovase al escribir el inicio de su copia, modificando el íncipit de $\alpha$. Queda fuera de duda que en $\alpha$, que copia directamente $V$, aparecerían los mencionados datos bibliográficos de este códice. Sin embargo, dos detalles del íncipit y el éxplicit de $R$ nos orientan a una posibilidad complementaria de lectura: el hecho de que este copista menciona que copia «versos» que han sido sacados del códice, que desconoce, para transmitirlos en el manuscrito que ahora está leyendo; y que culmina su copia indicando por cuenta propia que "solo se saco hasta aqui» en dicho manuscrito, sabiendo que la historia continúa pero no ha sido reproducida en él. Es evidente que conoce la leyenda del Cid a través de otros testimonios tradicionales, y por ello es plausible comprender que también notaría que en $\alpha$ "faltan muchas hojas" previas al relato "desde el destierro", que ya faltan en el "libro antiguo" de Vivar del que procede, así como que sabe que la historia continúa pero en el manuscrito que consulta solo se registra un fragmento. El copista de $R$, pues, configuraría el íncipit y éxplicit de su copia como testimonios descriptivos que hace sobre el relato contenido en el manuscrito $\alpha$ que está leyendo, así como sobre su propia labor de copia. Esto es, sabe que está transmitiendo una narración heroica bien conocida en la tradición, recogida en un testimonio $\alpha$ que a su vez atestigua la existencia del códice $V$, más completo, pero que no ha visto; pero esta narración heroica se le presenta de forma trunca, y por eso mismo indica que 
copia «versos» parciales del Cantar completo, el cual puede describir a partir de los datos que se incluirían en el íncipit original de $\alpha$.

En ese sentido, $T$ y $C$ podrían reflejar un íncipit más cercano al que sería el de $\alpha$, lo que nos da más pistas de la naturaleza de este documento. Obviamente, puesto que todos dependen de este subarquetipo, contendría esencialmente la misma información que el de $R$ : es una copia de la "historia» del $\mathrm{Cid}^{22}$, que se conserva en un pergamino en Vivar. Y en él se indica explícitamente que lo que ha sido "sacado de un libro antiguo" es el "traslado de la Historia", esto es, su copia fiel, empleándose para ello una fórmula notarial prototípica ya empleada desde, como muy pronto, mediados del siglo XIII («Esto es un traslado [...] sacado de [...] el tenor del es el que sigue»), y que se entiende mejor si se encontrase ya en $\alpha$, que por su naturaleza podría haberse concebido como "traslado". La antigüedad de esta fórmula nos permite suponer que fue la empleada en el íncipit de $\alpha$, el subarquetipo anterior en el tiempo a las copias que estamos cotejando, y que en $R$ se modificaría para describir lo que se está transmitiendo ("versos» sueltos), y en $T$ y $C$ se reduciría en contenido (suprimiendo las menciones al carácter incompleto del códice de Vivar).

Aun así, debemos admitir que la opción más sencilla es la primera, pues no implica presuponer complejos estadios de adición y supresión de datos entre testimonios; más aún, cuando el estema se antoja complejo, entre todas las copias conservadas y los dos subarquetipos hipotéticos que podemos intuir tras el cotejo de estas, así como por la brevedad de la muestra de versos cotejada. Por otra parte, téngase en cuenta que la fórmula de "traslado"se emplea también en los siglos XV-XVI, por lo que pudo emplearse de forma particular en $\beta$. Igualmente, no hemos sido capaces de determinar el origen de la copia $C^{23}$, pero si su actual localización en la Biblioteca Colombina implica que fue realizado en Sevilla, esto lo acerca más al ámbito erudito en el que Trigueros presentó su Disertación con la noticia del códice de Vivar, y, por tanto, esto facilita que el copista de $C$ pudiese acceder al "traslado» que poseía Trigueros. En suma, el caso de los íncipits puede resolverse de dos maneras, siendo la más probable el presuponer un subarquetipo $\beta$ que nos serviría, además, para explicar otros dos errores conjuntivos entre $T$ y $C$, aunque estos también conviene comentarlos.

La alternancia entre "puestas/puestos» es reveladora en cuanto a que orienta la datación de los testimonios posteriores al códice de Vivar. Así, puesto que Menéndez Pidal señaló que "puestas» era un añadido al verso original («burgueses e burguesas en las finiestras sone»), y ya que Ulibarri mantiene esta lectura, podemos

22. Tanto da en verso o en prosa; como hemos visto en BAKER (2001), la "historia» como género puede expresarse en ambos registros.

23. Le agradecemos al personal de la Biblioteca Colombina que nos orientase en esta cuestión, indicándonos que la única información bibliográfica disponible sobre este facticio es la que aparece consignada en su ficha bibliográfica, que se puede consultar en el catálogo digitalizado, y en la que no aparece ningún dato sobre su procedencia. 
confirmar que en una fecha indeterminada anterior a 1596 se había producido ya ese cambio. Pero Sánchez, en 1779, también lee "puestas", mientras que $T$ y $C$, en 1766 y una fecha desconocida del siglo XVIII, respectivamente, leen "puestos»; esta es una modificación que Menéndez Pidal señaló que fue repasada a tinta sobre el "puestas» anterior. Janer (1864), al reeditar a Sánchez a la vista del códice de Vivar, lee "puestos" porque es lo que aparecía en $V$ en aquel momento. Por tanto, no sabemos cuándo datar la modificación por "puestos» en el códice, si dos testimonios intermedios entre Ulibarri y Sánchez (que leen "puestas") muestran la lectura en masculino. La cuestión radica en por qué $\beta$ recogería una lectura, "puestos", que en teoría ya figuraría en $V$, y sin embargo Sánchez, posterior en el tiempo y que también consulta el códice $V$, lee "puestas", que es una variante fechable, como muy tarde, a finales del siglo XVI.

Como consecuencia de esta contradicción, cabe cuestionarse dónde encaja en ella el subarquetipo $\beta$, así como plantearnos si en $T$ y $C$ la modificación es poligenética: esto es, si ambos copistas dieciochistas leyeron en masculino plural, interpretando un recurso retórico (como silepsis que marca concordancia en un episodio donde se describe a una multitud de gente). Si aceptamos este subarquetipo $\beta$ común a $T$ y $C$, habría que resolver si en él se leía "puestos", lo que lo haría posterior a Ulibarri, 1596; pero esto es contradictorio con que Sánchez lea "puestas", solución anterior en el tiempo, si ya entre 1596 y 1766 se había realizado la modificación por «puestos» en $V$, haciendo ilegible (siempre según lo que indica Menéndez Pidal) la versión anterior "puestas". A no ser que Sánchez se dejase llevar por la lectura de Ulibarri en este caso concreto, en lugar de transcribir directamente el códice $V$ (solución que podría resultar rebuscada, en nuestra opinión, pero no imposible, pues Sánchez seguiría aquí la norma gramatical de la época, concordando con el femenino plural del sustantivo antecedente). Pero $\beta$ procede de $\alpha$, y en este texto, al igual que en Ulibarri, se mantiene la lectura "puestas" que fue añadida a este verso del Cantar. En $\beta$ no ocurre así, y la posición de este subarquetipo en el estema lo aleja de cualquier dependencia con este cambio "puestas > puestos» que se produjese en $V$. Más bien, tal vez la modificación por «puestos» en el subarquetipo $\beta$, si de ahí se transmitió a $T$ y $C$, debió de ser por causa de una variación monogenética, una innovación particular que luego coincidiría casualmente con la modificación realizada por repaso con tinta sobre el «puestas» de $V$. La datación cronológica de $\beta$, por tanto, no dependería de esta alternancia entre "puestos/puestas", que origina soluciones a menudo contradictorias entre los testimonios modernos, y difíciles de filiar.

Solo nos resta comentar la supresión de "campeador» en $T$ y $C$ : una variante muy significativa y que por sí sola podría sostener la existencia de $\beta$. Pero, a la vista de que las otras dos variantes también pueden ser discutidas, consideramos que solo esta elipsis, ciertamente difícil de justificar como resultado de poligénesis (aunque no imposible, como ya indicamos, pues el verso es hipermétrico, lo que pudo motivar esta modificación), es insuficiente cuantitativamente, aunque tal vez no cualitativamente, para plantear sin duda la existencia de tal subarquetipo. 
En conclusión, proponemos otra filiación de los testimonios $R, T$ y $C$, considerándolos copias sobre $\alpha . R$ presenta numerosos errores particulares de copia que no se transmiten a $T$ y $C$. Por otra parte, $T$ y $C$ presentan errores comunes que no pueden justificarse solo como coincidencias poligenéticas: muchas de ellas sí se explican por la procedencia común de estos tres testimonios desde $\alpha$ y porque los testimonios dieciochescos no caen en la misma tendencia de alta deturpación textual (con prurito arcaizante) que muestra el copista de $R$ en su trabajo; pero otras, escasas en cantidad pero muy significativas, nos plantean la posibilidad de que de $\alpha$ derivase $\beta$, y de este, a su vez, $T$ y $C$.

En cuanto al resto de filiaciones en el estema, añadimos algunas notas más. Sí podemos proponer con más seguridad que $R$ fue una copia que tuvo cierta circulación. Véase el testimonio del padre Sarmiento, quien, al copiar los diez versos del Cantar, indica:

En este género $[i$.e. los romances] he visto otras poesías, aunque solo citadas, las cuales seguramente son muy antiguas. A esta clase pertenece un fragmento poético de la Historia del Cid, que he visto manuescrito. Sacóse de un códice en pergamino, que se guarda en el Archivo del Concejo de Vivar, patria del mismo Cid Campeador; pero sumamente alterado dicho fragmento, así en la medida, como en los consonantes.

Si Sarmiento está copiando sobre $R$, como ya hemos propuesto, esto explica por qué da la misma información que aparece el íncipit de los tres testimonios $R / T / C$, y especialmente el de $R$, incluso parafraseándolo: fragmento "manuescrito", extraído de un códice "en pergamino" que se conserva «en el Archivo del Concejo de Vivar", y que contiene la "Historia del Cid». Coincidimos, pues, con la conclusión aportada por Montaner (2011: CCXCVII, n. 245), y reforzada con la lectura del manuscrito $R$ : Sarmiento no puede estar refiriéndose a Ulibarri, pues este «no indica el tipo de soporte del códice ni su copia es fragmentaria, lo que sí corresponde al testimonio mencionado por Trigueros». Ahora podemos suponer que Sarmiento, en su segunda aproximación al Cantar, recurre a $R$ (o puede, incluso, que a $\alpha$, que es el testimonio relacionado directamente con el "códice en pergamino" y también en él se indicarían los datos de procedencia de este): la muestra de cotejo es muy pequeña, pero arroja interesantes conclusiones en este sentido.

En cuanto al resto del estema, evidentemente sí debemos relacionar $T$ con $T$, su copia directa. El cotejo realizado ofrece exactamente el mismo texto. Los versos que Trigueros vuelve a copiar en sus Poesías filosóficas, el testimonio T2, provendrían del "traslado" manuscrito $\beta$ que posee. Y podemos, incluso, plantear filiaciones entre los testimonios restantes, como hemos hecho en el caso de las noticias que da Sarmiento del Cantar, y que provendrían, en primer lugar (Sarmiento 1; el manuscrito de 1745), de Ulibarri, y en segundo lugar (Sarmiento 2; sus Obras póstumas), de $R$. Por último, Sánchez remite a la consulta directa del 
códice de Vivar, que estaba en su poder ${ }^{24}$, y el manuscrito de Oviedo, como señaló Montaner, es una copia casi exacta de esta edición de 1779.

\section{CONCLUSIONES}

Las copias dieciochescas en las que se transmitió fragmentariamente el Cantar de mio Cid, así como algunas noticias impresas sobre el mismo, amplían sustancialmente el panorama crítico sobre la transmisión del texto cidiano en el Siglo de las Luces en dos sentidos. Una, porque, por sí mismas, son testimonios del contacto directo o indirecto de diversos autores con el códice de Vivar y el texto del héroe burgalés. Y dos, y aún más interesante, porque el cotejo de todos estos manuscritos e impresos nos permite suponer que la difusión del Cantar en el siglo XVIII fue mayor de lo que hasta ahora ha considerado la crítica.

Sobre los testimonios dieciochescos del Cantar (dos menciones de fray Martín Sarmiento en sus obras completas y las póstumas; la Disertación sobre el verso suelto y la rima autógrafa de Trigueros y una copia de esta; El poeta filósofo de Trigueros; una copia parcial del Cantar junto a la Estoria de Fernán González, conservada en la Biblioteca Colombina; la edición del Cantar realizada por Sánchez y una posible copia manuscrita de este conservada en la Biblioteca Universitaria de Oviedo), hemos realizado un cotejo entre aquellos que compartían una particularidad: transmitir solo los 197 primeros versos del Cantar. Así, hemos comparado los testimonios de Trigueros y el facticio de la Colombina con el Cantar original y una copia con el mismo número de versos, localizada en la Real Academia de la Historia y fechable entre el siglo XVI y el XVII, según la crítica.

El cotejo de los manuscritos nos permite establecer un estema de filiaciones en el que localizamos un posible subarquetipo $\alpha$ del que derivaron el manuscrito de la RAH, la copia del Cantar en la Disertación de Trigueros y el manuscrito de la Colombina. El proceso de collatio de los testimonios también nos permite detectar una larga lista de errores separativos del manuscrito de la RAH frente a las copias de Trigueros y la Colombina, que nos lleva a tratar de forma independiente la posición de cada uno de ellos en el estema. Por tanto, la existencia del mencionado subarquetipo, que hemos justificado en nuestra propuesta de stemma codicum, nos permite abordar desde otra perspectiva la transmisión del poema cidiano en el siglo XVIII. El copista del manuscrito de la RAH, Trigueros y el anónimo copista

24. Remitimos a MONTANER (2011: CCCI): sobre el códice que se conservaba en el convento de Santa Clara de Vivar en el siglo XviII, indica que "lo sacó de allí Eugenio de Llaguno y Amírola [...] para que el también académico y bibliotecario de la Biblioteca Real Tomás Antonio Sánchez pudiese emplearlo en la edición que proyectaba». Sánchez declara que, aunque ha corregido junto a José Antonio Pellicer la copia de Ulibarri, ha realizado su edición a partir de un nuevo traslado del códice medieval. El códice no fue devuelto por Llaguno a las monjas de Santa Clara, una vez Sánchez terminó su trabajo. 
del manuscrito de la Colombina partieron de una copia manuscrita que podríamos fechar como muy pronto a finales del siglo XV, y con más seguridad comienzos del XVI: el códice único del Cantar ya estaría en Vivar en 1512, y todos estos testimonios mencionan este hecho, que perfectamente pudo originar la elaboración de una copia para preservar el contenido del texto una vez pasó al Concejo. Hoy en día este documento continúa en paradero desconocido, si es que se ha conservado. Todo ello no va en detrimento de la posibilidad de que este "traslado» contase a su vez con otras copias derivadas, subarquetipos que explicasen la existencia de otras variantes entre los testimonios. Entre ellas, localizamos errores conjuntivos entre las copias dieciochescas de Trigueros y la Colombina que nos llevan también a hipotetizar que pudieron derivar a su vez de otro subarquetipo $\beta$, copiado de $\alpha$, y realizado en fecha desconocida, aunque bien pudo ser en fechas cercanas a $\alpha$, pues Trigueros lo tuvo en su poder y lo dató a comienzos del «siglo 1500".

Puesto que la muestra cotejada de 197 versos es pequeña, es muy difícil realizar la elección de las lecturas correctas para reconstruir el "traslado» de $\alpha$ (constitutio textus). No obstante, la filiación textual entre los testimonios localizados nos permite proponer nuevas vías por las que el Cantar fue conocido por eruditos e ilustrados. Esto también implicaría nuevas aportaciones al conocimiento archivístico que tuvieron los historiadores de la literatura medieval en el siglo XVIII, a través de documentos hoy perdidos, pero cuya existencia podemos recuperar a través del método de trabajo de la crítica textual.

\section{BiBLIOGRAFÍA}

Cronica del famoso canallero Cid Ruy Diez Campeador. Burgos: Imprenta de Fradrique Alemán de Basilea, 1512.

Historia del Cid, en versos antiguos. Madrid: Real Academia de la Historia, Ms. N-34.

Aguilar PiÑal, Francisco. "Cándido María Trigueros y el Poema del Cid». Nueva Revista de Filología Hispánica, 1984, 23, pp. 224-233.

Aguilar Piñal, Francisco. Un escritor ilustrado: Cándido María Trigueros. Madrid: CSIC, 1987.

Aguilar Piñal, Francisco. El académico Cándido María Trigueros (1736-1798). Madrid: Real Academia de la Historia, 2001.

BAKER, Edward. «Nuestras antigüedades: la formación del canon poético medieval en el siglo XVIII. Hispania, 2001, LXI/3, 209, pp. 813-830.

BleCUA, Alberto. Manual de crítica textual. Madrid: Castalia, 2001.

Berganza, Francisco de. Antigüedades de España, propugnadas en las noticias de sus reyes y condes de Castilla la Vieja [...]. Madrid: Imprenta de Francisco del Hierro, 1719, parte primera.

Instituto de INVESTigación RAFAel LAPESA DE la ReAl ACADEmia Española. Corpus del Nuevo diccionario histórico (CDH), 2013. http://web.frl.es/CNDHE, recuperado el 4 de junio de 2019.

Janer, Florencio. Poetas castellanos anteriores al siglo XV. Madrid: M. Rivadeneira, 1864. Biblioteca de Autores Españoles, LVIII. 
LAMA Hernández, Miguel Ángel. «Bartolomé José Gallardo y la Colección de Cortes de los Reinos de León y Castilla (1836)». Boletín de la Real Academia de Extremadura de las Letras y las Artes, 2015, 23, pp. 183-212.

López Martínez, M. a Isabel y Hernández SÁnchez, Eulalia. Benito Martínez Gómez Gayoso en la teoría gramatical del siglo XVIII. Murcia: Secretariado de Publicaciones de la Universidad de Murcia.

Martínez Gómez Gayoso, Benito. Gramática de la lengua castellana reducida a breves reglas, y facil methodo para instruccion de la Juventud. Madrid: Imprenta de Gabriel Ramírez, 1769.

Menéndez Pidal, Ramón. La leyenda de los Infantes de Lara. Madrid: Hijos de José M. Ducazcal, 1896.

MenÉNDEZ PIDAL, Ramón. Cantar de mio Cid. Texto, gramática y vocabulario, volumen III. Madrid: Imprenta de Bailly-Baillière, 1911.

Menéndez Pidal, Ramón. Poema de Mio Cid. Madrid, [s. n.], 1961. [En línea]. Alicante \& Madrid: Biblioteca Virtual Miguel de Cervantes \& Biblioteca Nacional de España, 2002. http://www.cervantesvirtual.com/obra/poema-de-mio-cid--0/, recuperado el 10 de enero de 2019.

Montaner Frutos, Alberto (ed.). Cantar de Mio Cid. Barcelon: Crítica, 2007. Colección Clásicos y Modernos.

MontAner Frutos, Alberto (ed.). Cantar de Mio Cid. Madrid: Real Academia Española; Barcelona: Galaxia Gutenberg-Círculo de Lectores, 2011.

Montaner Frutos, Alberto. "The Poema de mio Cid as Text: Manuscript Transmission and Editorial Politics». En ZADERENKO, Irene y MonTANER, Alberto (eds.) y MAHONEY, Peter (col.). A companion to the "Poema de Mio Cid". Leiden \& Boston: Brill, 2018, pp. 43-85.

REAL ACADEMIa ESPAÑola. Gramática de la Lengua Castellana. Madrid: Joaquín de Ibarra, 1771.

Riaño Rodríguez, Timoteo y Gutiérrez AjA, M. ${ }^{a}$ del Carmen (eds.). El Cantar de Mio Cid. Tomo I: El manuscrito del Cantar. [En línea]. Alicante: Biblioteca Virtual Miguel de Cervantes, 2003. Edición original en Burgos: Diputación Provincial de Burgos, 1998. http://www.cervantesvirtual.com/portales/cantar de mio cid/obra/el-cantar-de-mocid-tomo-i--el-manuscrito-del-cantar-0/, recuperado el 10 de enero de 2019.

ROMÁN GUTIÉRREZ, Isabel. "Un episodio español de la "querella entre antiguos y modernos": Cándido María Trigueros y su teoría sobre la versificación». eHumanista, 2017, 37, pp. 103-119.

RUIZ DE UliBARRI y LEYVA, Juan. Historia del famoso cauallero Rodrigo de Bibar llamado por otro nombre Cid Campeador. Madrid: Biblioteca Nacional de España, MSS/6328, 1596.

SALVADOR Plans, Antonio. La "fabla antigua" en los dramaturgos del Siglo de Oro. Cáceres: Servicio de Publicaciones de la Universidad de Extremadura.

SÁncheZ, Tomás Antonio. Colección de poesías castellanas anteriores al siglo XV, tomo I, Poema del Cid. Madrid: Imprenta de Antonio de Sancha, 1779.

Sarmiento, Martín. Obras. Madrid: Biblioteca Nacional de España, MSS/20377.

Sarmiento, Martín. Obras póstumas del Rmo. P. M. Fr. Martín Sarmiento benedictino. Madrid: Imprenta de Joaquín Ibarra, 1775, tomo primero.

Trigueros, Cándido María. Disertación sobre el verso suelto y la rima. Madrid: Biblioteca Nacional de España, MSS/20056, 1766.

Trigueros, Cándido María. El poeta filósofo o poesías filosóficas. Sevilla: Imprenta de Manuel Nicolás Vázquez y compañía, 1775. 
Trigueros, Cándido María. Disertación sobre el verso suelto y la rima. Edición de Isabel Román Gutiérrez. [En línea]. Universidad de Córdoba: Proyecto de Investigación PHEBO, 2017. http://www.uco.es/phebo/sites/default/files/trigueros.pdf, recuperado el 10 de enero de 2019.

Zamora Vicente, Alonso. «Sobre la fabla antigua de Lope de Vega». En Philologica hispaniensia: in honorem Manuel Alvar, vol. 1. Madrid: Gredos, 1983, pp. 645-650. 